\title{
Magmas functions as a ROS regulator and provides cytoprotection against oxidative stress-mediated damages
}

\author{
S Srivastava ${ }^{1}$, D Sinha ${ }^{1}$, PP Saha ${ }^{1}$, H Marthala ${ }^{1}$ and P D'Silva*,
}

Redox imbalance generates multiple cellular damages leading to oxidative stress-mediated pathological conditions such as neurodegenerative diseases and cancer progression. Therefore, maintenance of reactive oxygen species (ROS) homeostasis is most important that involves well-defined antioxidant machinery. In the present study, we have identified for the first time a component of mammalian protein translocation machinery Magmas to perform a critical ROS regulatory function. Magmas overexpression has been reported in highly metabolically active tissues and cancer cells that are prone to oxidative damage. We found that Magmas regulates cellular ROS levels by controlling its production as well as scavenging. Magmas promotes cellular tolerance toward oxidative stress by enhancing antioxidant enzyme activity, thus preventing induction of apoptosis and damage to cellular components. Magmas enhances the activity of electron transport chain (ETC) complexes, causing reduced ROS production. Our results suggest that $J$-like domain of Magmas is essential for maintenance of redox balance. The function of Magmas as a ROS sensor was found to be independent of its role in protein import. The unique ROS modulatory role of Magmas is highlighted by its ability to increase cell tolerance to oxidative stress even in yeast model organism. The cytoprotective capability of Magmas against oxidative damage makes it an important candidate for future investigation in therapeutics of oxidative stress-related diseases.

Cell Death and Disease (2014) 5, e1394; doi:10.1038/cddis.2014.355; published online 28 August 2014

Reactive oxygen species (ROS) are the chemical species formed by the incomplete reduction of oxygen and includes superoxide anion $\left(\mathrm{O}_{2}^{-}\right)$, hydrogen peroxide $\left(\mathrm{H}_{2} \mathrm{O}_{2}\right)$, singlet oxygen and hydroxyl radicals $(\cdot \mathrm{OH}){ }^{1,2} \mathrm{ROS}$ is generated primarily as a by-product of cellular metabolism through leakage of electrons by electron transport chain (ETC) in mitochondria and from other sources such as plasma membrane, peroxisomes and endoplasmic reticulum. ${ }^{3,4}$ ROS acts as signaling molecule when present at an appropriate level through the covalent modification of specific cysteine residues of redox-sensitive target proteins. ${ }^{5}$ The optimum level of ROS is maintained by equilibrium between its production and scavenging through the involvement of antioxidant system. An alteration in this equilibrium gives rise to oxidative stress, leading to cellular damage that finally precipitates into neurodegenerative disorders, cancer and metabolic disorders such as diabetes. ${ }^{6-11}$

Therefore, for the maintenance of redox equilibrium, surveillance on generation of ROS is as critical as ROS scavenging. Mitochondria being the primary source of ROS generation by ETC assume the important center for maintenance of ROS levels. The factors that control ROS production by ETC complexes are not well defined. Mitochondria harbors a number of ROS scavenging enzymes such as intermembrane space-associated $\mathrm{Cu}$-Zn superoxide dismutase (Cu-Zn SOD), matrix-localized MnSOD, isoforms of peroxiredoxins and glutaredoxins. ${ }^{12}$ Together, these proteins help in maintaining the appropriate cellular ROS level. Maintenance of optimum level of ROS is important for developing tissues and stem cells and in metabolically active tissues where the high-energy demand makes them more vulnerable to oxidative stress. In addition to this, cancer cells having aberrant metabolism tend to have enhanced ROS that helps in tumor progression; however, abnormally high ROS may lead to apoptosis. ${ }^{13-17}$ Thus, in cancer cells, for their prolonged survival, there exists an evolved mechanism to maintain the balance of redox state through upregulation of many antioxidant enzymes ${ }^{9-11}$ and a number of signaling molecules modulating the expression level of these enzymes. ${ }^{18,19}$

In earlier reports, overexpression of 'Magmas' was observed in patient samples of prostate cancer, pituitary adenoma, in various developmental stages and in metabolically active human tissues. $^{20}$ Originally, Magmas was identified as a protein involved in granulocyte-macrophage colony-stimulating factor (GM-CSF) signaling and was found to localize in mitochondria. ${ }^{21,22}$ Magmas belongs to type IV class of J-proteins and acts as co-chaperone of mitochondrial

\footnotetext{
${ }^{1}$ Department of Biochemistry, Indian Institute of Science, Bangalore, India

*Corresponding author: P D'Silva, Department of Biochemistry, Indian Institute of Science, C.V. Raman Avenue, Bangalore 560012, India. Tel: +91 08022932821 ; Fax: +91 080 23600814; E-mail: patrick@biochem.iisc.ernet.in

Abbreviations: ROS, reactive oxygen species; ETC, electron transport chain; GPx, glutathione peroxidase; DCFDA, 2',7'-dichlorofluorescin diacetate; NAC, N-acetyl cysteine; GSH, glutathione; GSSG, glutathione disulfide; SOD, superoxide dismutase; mtDNA, mitochondrial DNA; qPCR, quantitative PCR; GM-CSF, granulocytemacrophage colony-stimulating factor; HEK293T, human embryonic kidney 293T; NAO, N-nonyl acridine orange; PI, propidium iodide; mtHsp70, mitochondrial heat shock protein 70

Received 25.4.14; revised 25.6.14; accepted 14.7.14; Edited by A Finazzi-Agrò
} 
heat shock protein 70 ( $\mathrm{mtHsp} 70)$. It is an inner membraneassociated protein and an essential component of mitochondrial protein translocation machinery. Magmas inhibits the activity of its J-protein counterpart DnaJC19 in stimulating ATPase activity of $\mathrm{mtHsp} 70$ at the transport channel and regulates the import of nuclear-encoded mitochondrial proteins into the matrix. ${ }^{22}$

Although overexpression of Magmas in energy-demanding tissues and cancer cells is well known, the physiological advantage provided by the enhanced expression of the protein is still enigmatic. In the present study, we have provided compelling evidence favoring an additional function of Magmas as a 'ROS regulator'. The overexpression of Magmas led to reduction in ROS and increased cellular tolerance to oxidative stress, whereas its downregulation elevated the cellular ROS level and made the cells more susceptible to ROS-mediated apoptosis. To maintain the redox equilibrium and provide cytoprotection against oxidative stress, Magmas controls ROS production by enhancing the ETC complex activity. On the other hand, it increases the activity of two major antioxidant enzymes such as MnSOD and glutathione peroxidase (GPx) to promote ROS scavenging. In summary, we propose a novel essential role of Magmas as a 'ROS regulatory protein' in the maintenance of cellular redox homeostasis and imparting cytoprotection under oxidative stress.

\section{Results}

Magmas overexpression leads to lower basal level of ROS. To ascertain the role of overexpressed Magmas in assisting the growth of cancer cells, ${ }^{21}$ we assessed the level of Magmas in two prostate cancer-derived cell lines PC-3 and LNCaP. We found that Magmas expression in PC-3 was approximately twofold higher than LNCaP (Figures 1a and b).

We hypothesized that Magmas might be modulating ROS by virtue of its overexpression in cancer cells; as differential levels of ROS and upregulation of many ROS-modulating proteins play a critical role in cancer cell signaling and proliferation. $5,10-12,21,23$ To test our hypothesis, we compared total cellular ROS levels in PC-3 and LNCaP cells through 2',7'-dichlorofluorescin diacetate (DCFDA) staining followed by flow cytometric analysis. Interestingly, PC-3 cells showed twofold lesser amount of cellular ROS as compared with LNCaP (Figure 1c). To determine mitochondria as a major source of the detected ROS levels, organeller superoxide production was quantified flow cytometrically by MitoSOX RED staining. ${ }^{24}$ Consistent to DCFDA data, mitochondrial superoxide level was found to be twofold lower in PC-3 as compared with LNCaP cells (Figure 1d).

The contribution of Magmas overexpression toward maintenance of cellular redox state was assessed by siRNAmediated knockdown of Magmas in PC-3 cells (Figure 1e). In support of our hypothesis, we observed more than 1.5-fold increase in ROS level upon downregulation of Magmas in PC-3 cells (Figures if and $g$ ) that was further verified by fluorescence microscopic observations. Magmas downregulation leads to enhancement of fluorescence intensity of DCFDA staining (Figure 1h, lower panel) as compared with control cells (Figure 1h, upper panel). Similarly, there was an increment in MitoSOX staining in cells downregulated for Magmas (Figure 1i, lower panels) than controls, indicating the increase in mitochondrial ROS (Figure 1i, upper panels, Supplementary Figures S1a and b). As a negative control for the stress induced by ProLong Gold, a parallel experiment was performed using phenol red-free growth medium. We observed a similar increase in ROS upon Magmas downregulation in PC-3 cells (Supplementary Figures S1c and d).

Magmas forms an essential part of mitochondrial protein import machinery. The loss of protein function results in impairment of preprotein translocation, mitochondrial function, cell cycle arrest and skeletal dysplasia in Drosophila and humans. ${ }^{22,25,26}$ To rule out the possible association of enhanced ROS with import defects, we analyzed the accumulation of nonprocessed precursor form of a model mitochondrial protein $\mathrm{mtHsp} 70$ under Magmas-depleted condition. We partially depleted Magmas to a level that does not result in protein import defects as indicated by absence of mtHsp70 precursor form (Figure 1j); however, the cells were associated with enhanced ROS levels (Figures $1 \mathrm{f}$ and $\mathrm{g}$ ). Together, these findings suggest that elevated expression of Magmas leads to decrease in cellular ROS and downregulation of the protein leads to increment in ROS level that is independent of its import function.

Reduction of cellular ROS upon extraneous expression of Magmas: importance of the J-like domain. To further confirm that enhanced expression of Magmas leads to reduction in ROS level, we overexpressed the protein in human embryonic kidney 293T (HEK293T) cells and analyzed cellular and mitochondrial ROS levels (Supplementary Figure S2a, lane 2). Upon flow cytometric analysis of DCFDA staining, we observed that HEK293T cells with basal level of Magmas showed twofold higher cellular ROS as compared with cells having increased Magmas expression (Figure 2a). The results were further validated by using another

\footnotetext{
Figure 1 Modulation of ROS by differential Magmas expression. (a) Western blot of Magmas comparing the protein's expression level in PC-3 and LNCaP. Anti-Tim 23 antibodies were used as a loading control. (b) Quantification of western blot showing expression level of Magmas in PC-3 and LNCaP (blot shown in (a)). Quantification was performed using ImageJ software. (c) PC-3 and LNCaP cells were stained with DCFDA dye; relative amount of cellular ROS was measured by flow cytometry and represented as fold change in mean fluorescence intensity (MFI) of oxidized dye over LNCaP cells. (d) The mitochondrial superoxide level was measured by staining the cells with MitoSOX and quantified by analyzing the fluorescent intensity through flow cytometry. (e) Western blot showing the level of Magmas downregulation (Mag $\downarrow$ ) in PC-3 cells after siRNA transfection. (f and $\mathbf{g}$ ) Measurement of an increase in oxidative stress in PC-3 cells through DCFDA (f) and MitoSOX (g) staining after siRNA-mediated downregulation of Magmas, ROS level is presented as fold MFI over untransfected PC-3 cells (UT) and rotenone-treated cells were used as a positive control for the production of superoxides in mitochondria. A nontargeting siRNA (NT) was used as a negative control for siRNA-mediated knockdown. (h and i) Fluorescent images of PC-3 stained with DCFDA (h) and MitoSOX (i) after Magmas downregulation. (j) Western blot showing accumulation of precursor form of mtHsp70 in PC-3 cells with reduced expression of Magmas and exposed to heat stress for $2 \mathrm{~h}$; $p$, precursor form, $\mathrm{m}$, mature form of the protein. Data represented as mean \pm S.E.M., $n=3 ;{ }^{* \star} P<0.001$ (two tailed) and ${ }^{\star \star \star} P<0.0001$ (two tailed); scale bar: $10 \mu \mathrm{m}$
} 
ROS-specific dye Amplex RED (Supplementary Figure S2b). Similarly, HEK293T cells with elevated Magmas showed lesser MitoSOX staining than control cells (Figure 2b).
To ascertain that decrease in mitochondrial superoxide is not due to the decrease in mitochondria biogenesis, we stained Magmas-overexpressing cells with $\mathrm{N}$-nonyl acridine a

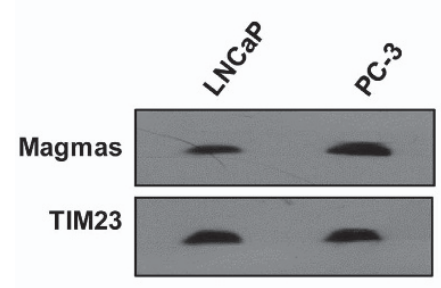

e

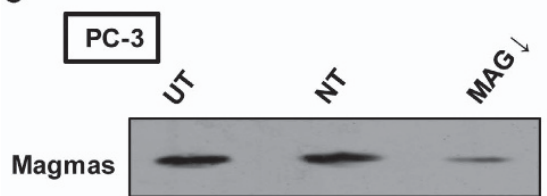

Tim23

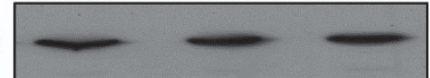

f

DCFDA Staining

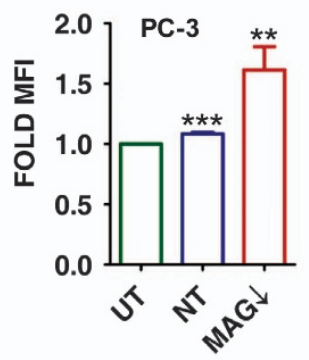

g

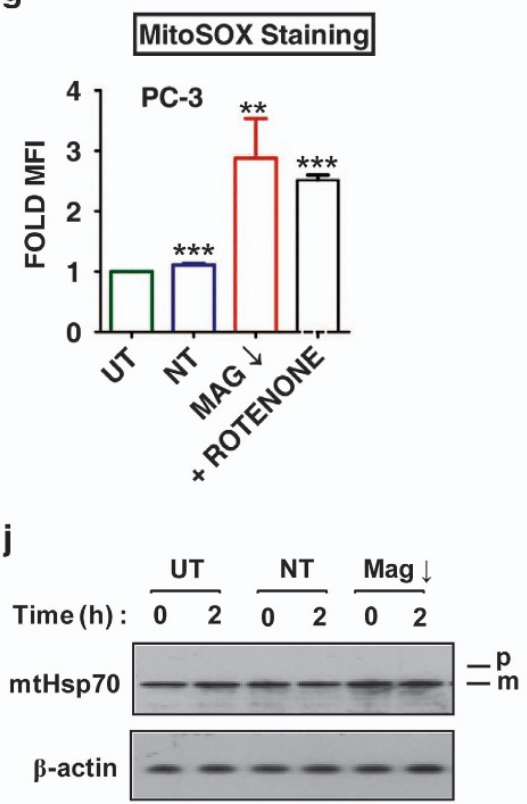

b

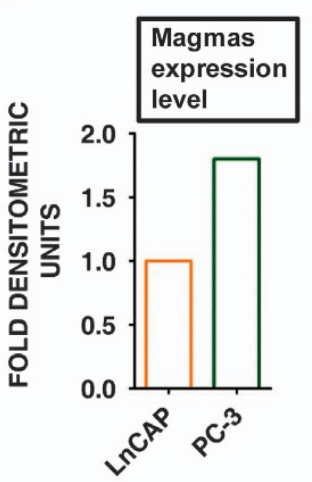

h

DCFDA Staining of PC-3 cells
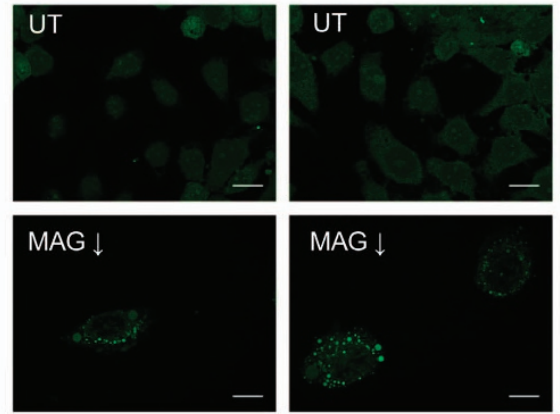

c
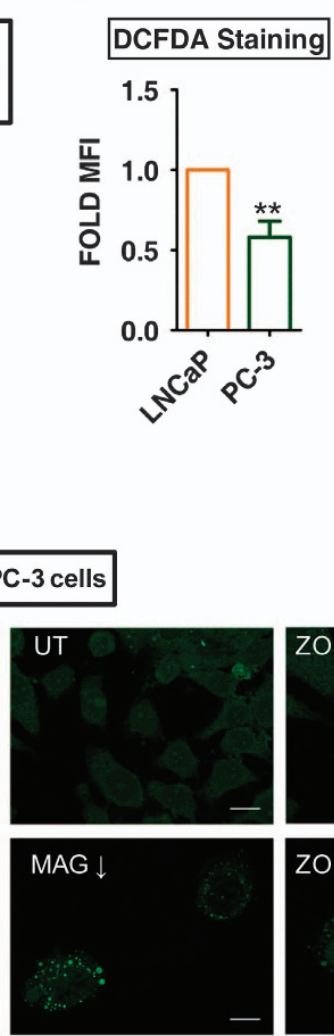

d

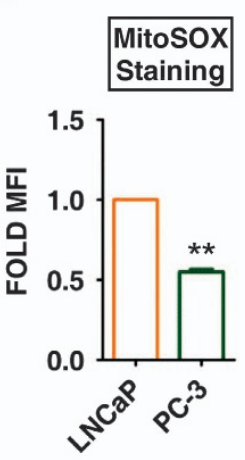

i
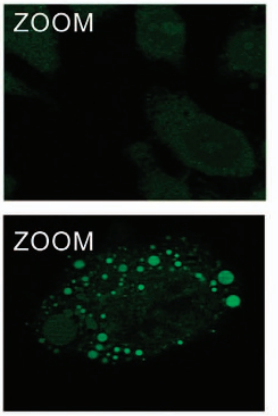

MitosoX staining of PC-3
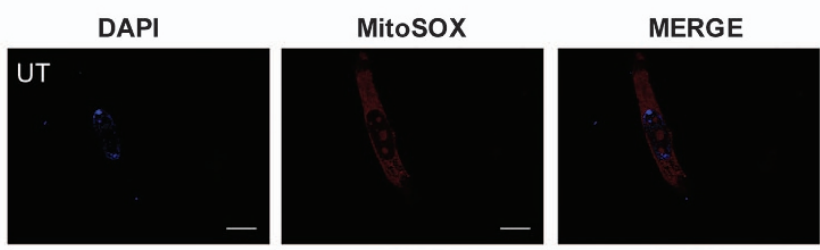

ZOOM
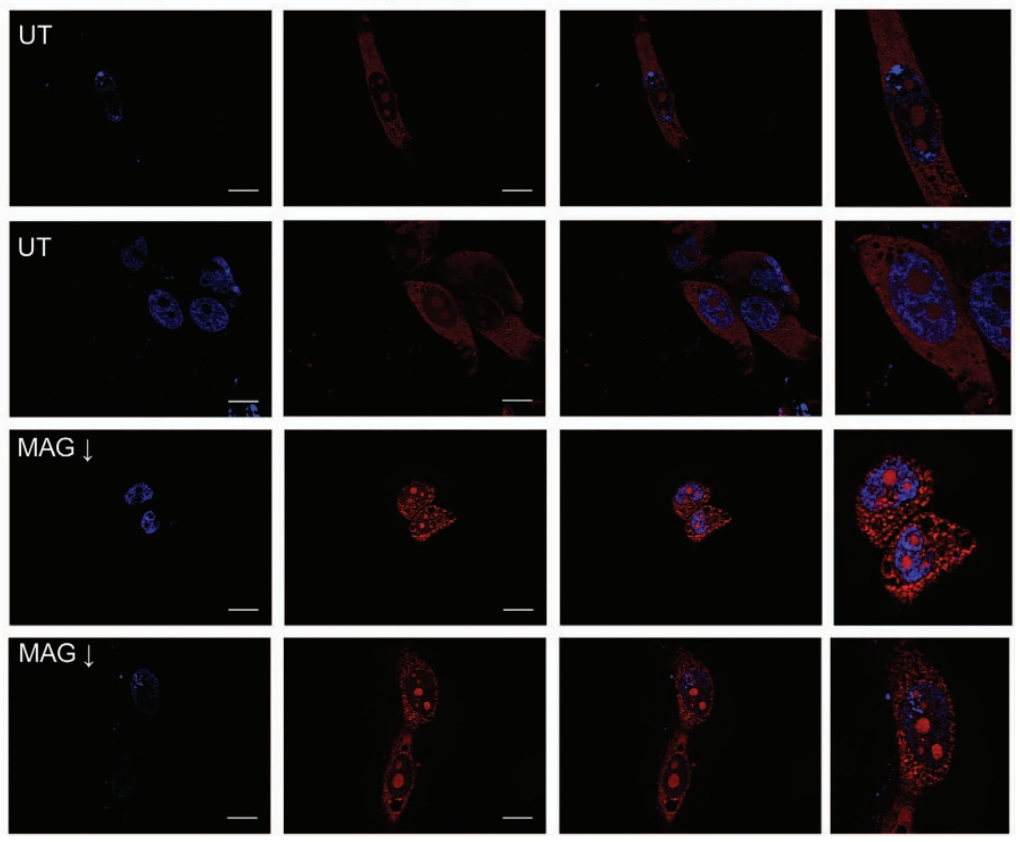
a

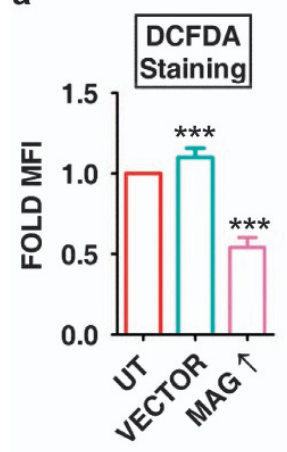

e
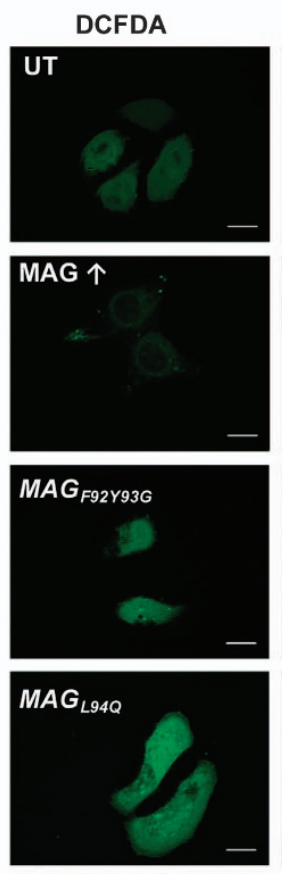

b

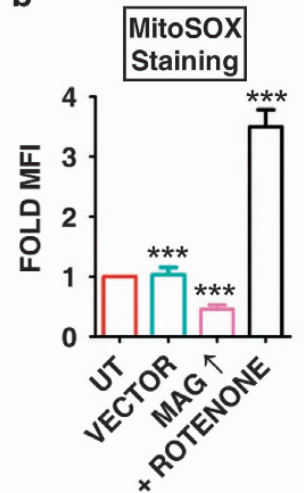

c
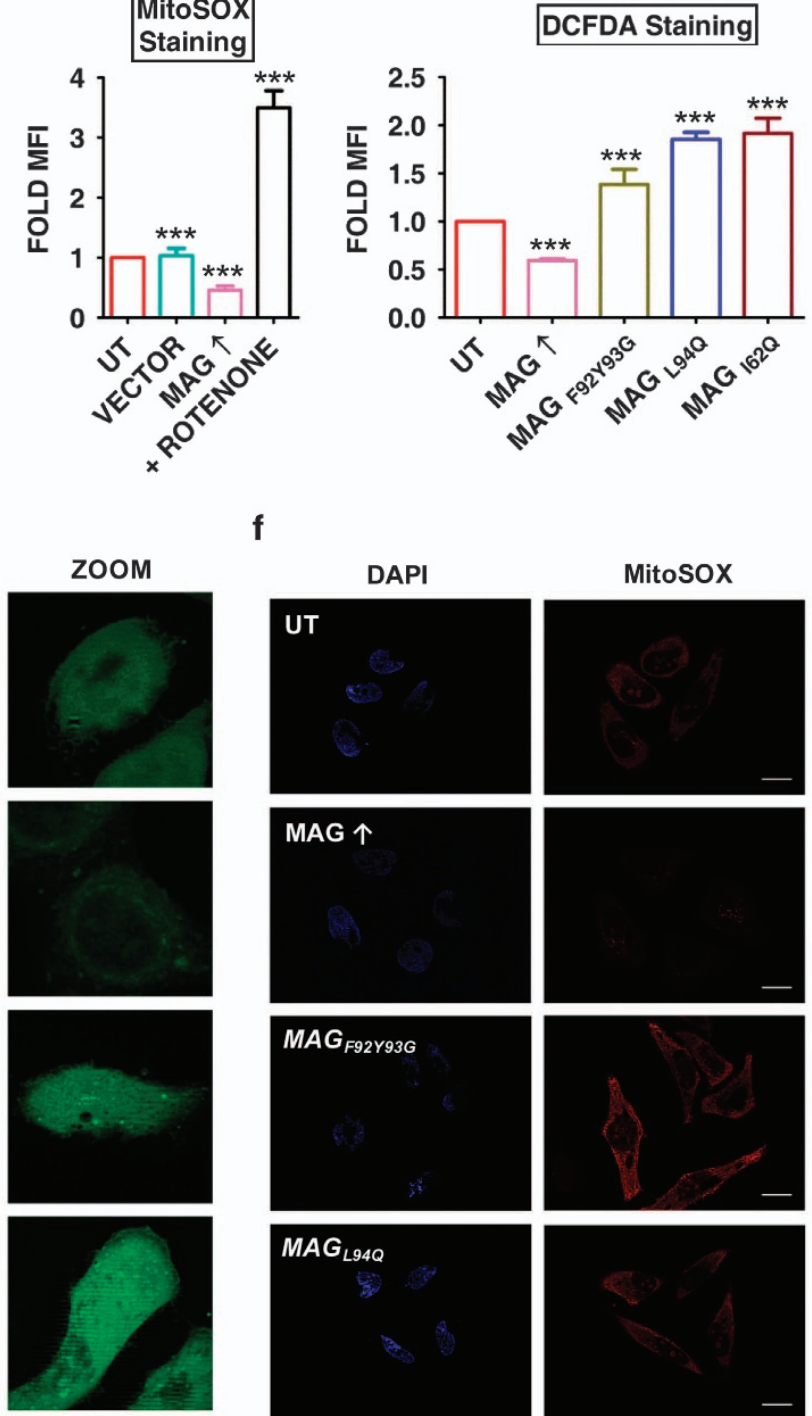

f
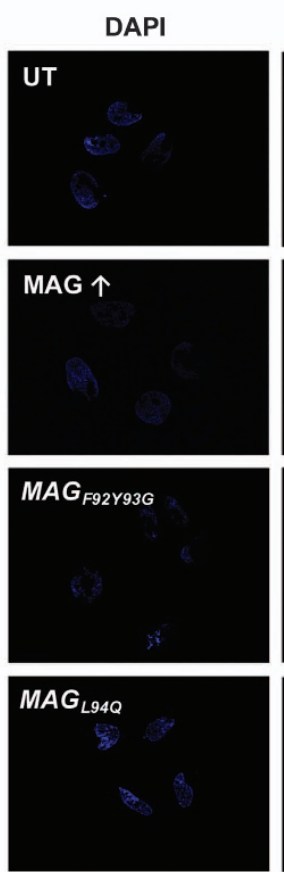

Mitosox
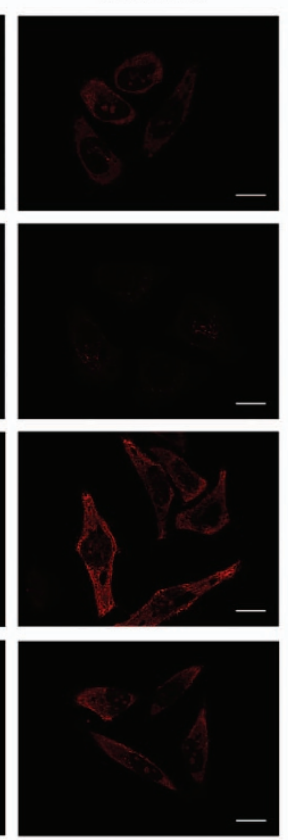

d

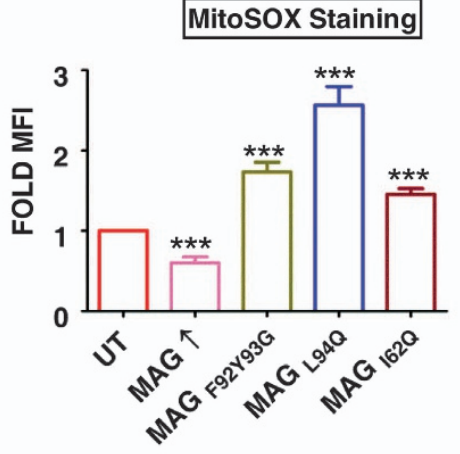

Figure 2 Modulation of ROS by extrinsic overexpression of Magmas: involvement of J-like domain. (a and $\mathbf{b})$ Quantification of decrease in ROS by increased Magmas expression (Mag $\uparrow$ ) in HEK293T cells presented as fold decrease in fluorescent intensity of DCFDA (a) and MitoSOX (b) over untransfected HEK293T cells. Empty vector was transfected as a transfection control. (c and d) HEK293T cells were transfected with Magmas mutants to generate a semidominant negative phenotype, and an increase in oxidative stress was observed by flow cytometry as depicted by fold changes in MFI values of DCFDA (c) and MitoSOX (d) over untransfected cells. (e and f) HeLa cells overexpressing Magmas and Magmas mutants were stained with DCFDA (e) and MitoSOX (f); the comparative ROS levels were inferred from the intensities of the oxidized fluorescent form of dyes presented as images of the cells. Data represented as mean \pm S.E.M., $n=3 ;{ }^{* \star \star} P<0.0001$ (two tailed); scale bar: $10 \mu \mathrm{m}$

orange (NAO). Contrastingly, we observed that Magmas overexpression elevates the mitochondrial biogenesis (Supplementary Figure S2c). Therefore, our findings suggest that Magmas, in spite of enhancing mitochondria content, is associated with reduced mitochondrial superoxide level.

As the functionality of J-proteins depends upon active $\mathrm{J}$-domain, we asked the question of whether J-like domain of Magmas is involved in its ROS regulatory role. To assess, we

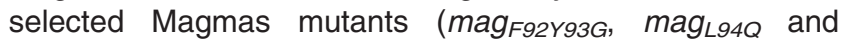
mag $\left._{162 Q}\right)$ and adjudged the effect of these mutations on ROS modulating role of Magmas by overexpressing the mutants in HEK293T cells (Supplementary Figure S2a, lanes 3-5). As observed through flow cytometry, none of the mutants displayed ability of ROS reduction; contrarily, cells expressing Magmas mutants showed high level of ROS as compared with control (Figures $2 \mathrm{c}$ and $\mathrm{d}$ ). The observations were validated by microscopic analysis of HeLa cells. The ROS levels in cells expressing Magmas mutants were substantially higher as compared with controls (Figures 2e and $f$, panels 3-5). At the same time, cells with elevated Magmas showed minimal fluorescence (Figures $2 e$ and $f$, panels 1 and 2, Supplementary Figures S2d and e). Similarly, a decrease in ROS level was observed when cells were mounted in phenol red-free medium as a control (Supplementary Figures S2f and g).

Magmas involvement in decreased production of ROS during cellular respiration. Redox balance can be 
maintained both by controlling the production and efficient scavenging of ROS. Thus, we investigated involvement of Magmas in controlled production of ROS and its scavenging. ROS is produced through the leakage of electrons from mitochondrial ETC. The inhibition of ETC complex activity is associated with enhanced ROS production due to slippage of electrons. ${ }^{3,27}$ Consequently, maintenance of robust activity of respiratory complexes leads to lesser amount of ROS generation by proper channeling of electron. Therefore, we measured activities of all four ETC complexes in mitochondria having higher expression of Magmas. We observed that PC-3 cells had higher activity of ETC complexes as compared with LNCaP (Figure 3a). Similarly, mitochondria isolated from HEK293T cells showed lesser activity of respiratory chain complexes as compared with those overexpressing Magmas (Figure $3 \mathrm{~b}$ ). Mitochondria expressing Magmas mutants had remarkably lower activities of ETC complexes as compared with controls (Figure 3c). This suggests the involvement of Magmas in controlled production of ROS.

As channeling of electrons through ETC is coupled to the production of ATP, we measured the ATP level in isolated mitochondria. PC-3 mitochondria showed higher ATP levels as compared with LNCaP. Similarly, enhanced expression of Magmas was associated with elevated mitochondrial ATP in HEK293T cells. Mitochondria isolated from mutant-expressing cells had a considerably lesser amount of ATP as compared with wild-type mitochondria (Figure $3 \mathrm{~d}$ ). The observed elevated level of mitochondrial ATP justifies the overexpression of Magmas in metabolically active tissues as reported earlier. ${ }^{28}$

\footnotetext{
Magmas overexpression prevents oxidative stressmediated cell death via promoting ROS scavenging. The criticality of ROS modulatory proteins comes into the fore when cell is exposed to extraneous stresses. Such proteins help in scavenging ROS and protect cell viability. Hence, we examined the ability of Magmas to reduce ROS and promote cell survivability under oxidative stress. PC-3 cells downregulated for Magmas were exposed to increasing concentrations of $\mathrm{NaAsO}_{2}(10-100 \mu \mathrm{M})$ to induce oxidative stress, ${ }^{29}$ followed by propidium iodide $(\mathrm{PI})$ staining. We observed that untransfected PC-3 cells were able to survive at higher concentrations of $\mathrm{NaAsO}_{2}$ than the cells expressing a lower amount of Magmas (Figure 4a), suggesting that Magmas overexpression increases cellular stress tolerance. Indeed, HEK293T cells with higher expression of Magmas showed better viability at higher concentrations of $\mathrm{NaAsO}_{2}$ as compared with control cells that showed enhanced lethality with the increase in the oxidative insult (Figure 4b). The above observations indicate that overexpression of Magmas rescues the viability of cells from oxidative stress. To accredit Magmas involvement in providing an escape from apoptosis, we exposed PC-3 cells with reduced Magmas expression to $25 \mu \mathrm{M} \mathrm{NaAsO} \mathrm{Na}_{2}$ and analyzed the activation of effector caspase $3 / 7$ as an apoptotic hallmark. We observed an increased activation of caspase $3 / 7$ upon downregulation of Magmas as compared with controls (Figure 4c). Similarly, overexpression of Magmas in HEK293T cells protected from
}

caspase activation under stress conditions as compared with controls (Figure 4d)

To determine whether the anti-apoptotic effect of Magmas under stress was due to maintained cellular redox state, we evaluated ROS levels in the cells. Upon $\mathrm{NaAsO}_{2}$ treatment, we observed an increment of ROS in untransfected HEK293T cells but not in cells overexpressing Magmas similar to that of $\mathrm{N}$-acetyl cysteine (NAC)-treated control cells, as analyzed by DCFDA (Figure 4e), MitoSOX (Figure 4f) and Amplex RED (Supplementary Figure S3a) staining. In contrast, cells expressing Magmas mutants showed elevated ROS than controls (Supplementary Figure $\mathrm{S} 3 \mathrm{~b}$ and $\mathrm{c}$ ). We further confirmed our findings through fluorescent microscopy in HeLa cells. Upon exposure to oxidative insult, cells with higher expression of Magmas showed a lesser amount of ROS as compared with the control as indicated by lesser intensity of DCFDA (Figure 4g, panels 1 and 2) and MitoSOX staining (Figure 4h, panels 1 and 2), and cells expressing Magmas mutants showed intense staining of ROS-sensitive dyes (Figures $4 \mathrm{~g}$ and $\mathrm{h}$, panels 3-5, Supplementary Figures S3d and e), whereas control cells mounted on phenol red-free medium showed lower ROS upon Magmas overexpression (Supplementary Figures S3f and g). In summary, our results highlight the critical role of Magmas in prevention of apoptotic cell death and increased cellular stress tolerance by maintaining the free radical balance.

Magmas expression rescues viability of yeast cells upon oxidative stress. Our previous study has shown that Magmas could complement the growth of $\Delta$ pam16 yeast strains and transport the precursor proteins as a part of the TIM23 complex, although they share only $\sim 41 \%$ sequence similarity at J-domain. ${ }^{22}$ We asked whether the ROS modulatory role of Magmas orthologs is unique to the mammalian system. We differentially expressed Magmas under moderate $A D H$ and stronger TEF promoter in $\triangle$ pam 16 cells (Supplementary Figures S4a and b). To adjudge the ability of Magmas and Pam16 in conferring cellular stress tolerance, yeast cells expressing Magmas or Pam16 were exposed to increasing concentrations of $\mathrm{H}_{2} \mathrm{O}_{2}(2-8 \mathrm{mM})$. Cells expressing Magmas revived even after an exposure of higher concentration of $\mathrm{H}_{2} \mathrm{O}_{2}$, whereas cells expressing wild-type Pam16 showed poor survivability (Figure 5a). To ascertain whether the protection of cell viability was mediated by decrease in ROS, the yeast cells treated with $4 \mathrm{mM} \mathrm{H}_{2} \mathrm{O}_{2}$ were stained with DCFDA and MitoSOX. Cells expressing Pam16 and Magmas under $A D H$ promoter showed higher fluorescence as compared with cells expressing Magmas under TEF promoter, indicating a decrease in ROS upon enhanced Magmas expression (Figures $5 b$ and $c$ ). Magmas mutants $\left(\right.$ mag $_{F 92 G}$, mag $_{F 92 Y 93 G}$ and mag $\left._{L 94 Q}\right)$ with a defective J-like domain were unable to rescue the cell viability under oxidative stress (Figure $5 \mathrm{~d}$ ) and showed intense staining of ROS-specific dyes at both permissive and nonpermissive temperatures (Figures $5 \mathrm{e}-\mathrm{g}$, Supplementary Figures S4c-f), verifying that defect in J-like domain of Magmas obstructs its ROS regulating function.

The role of Magmas in controlled production of ROS was analyzed using yeast mitochondria. The mitochondria expressing Pam16 and lower level of Magmas (under $A D H$ promoter) 
a

\section{PC-3 AND LNCaP}
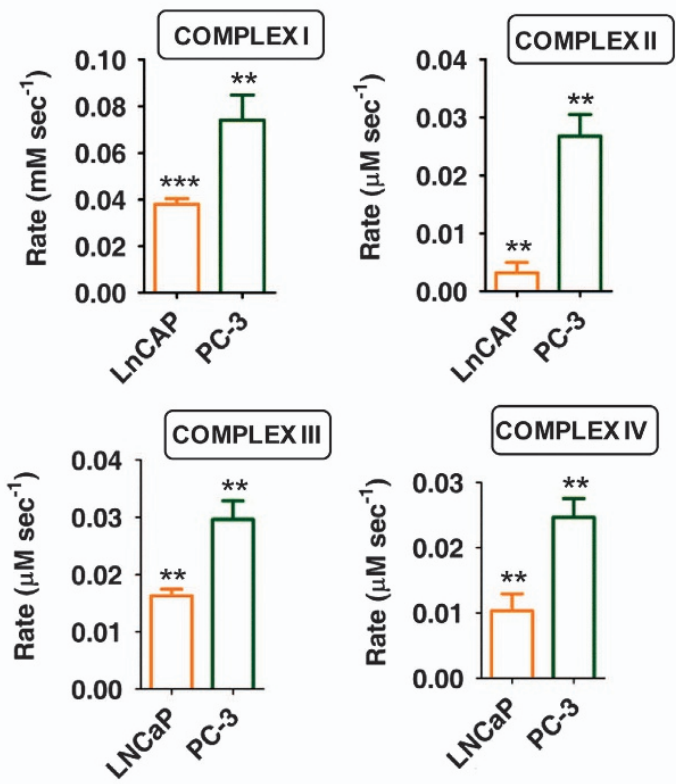

C

\section{HEK293TEXPRESSING Magmas MUTANTS}
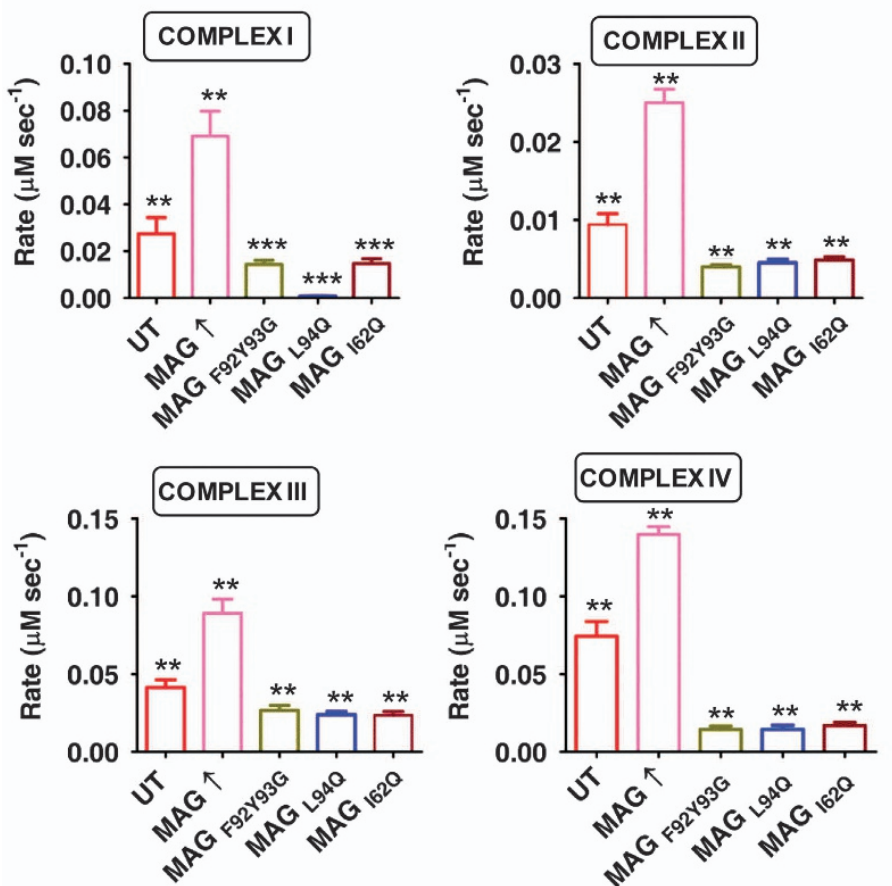

b

OVEREXPRESSION OF Magmas IN HEK293T
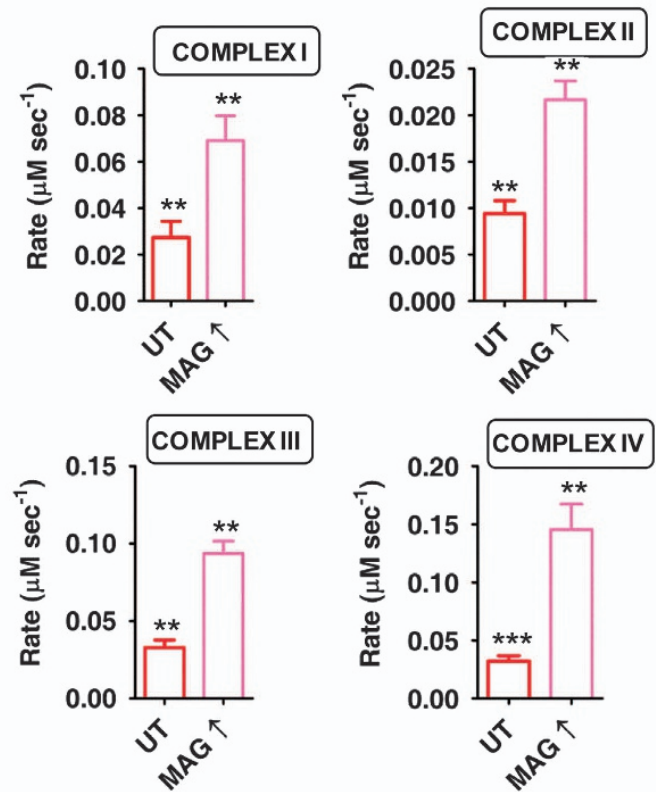

d

\section{MITOCHONDRIAL ATP LEVEL}
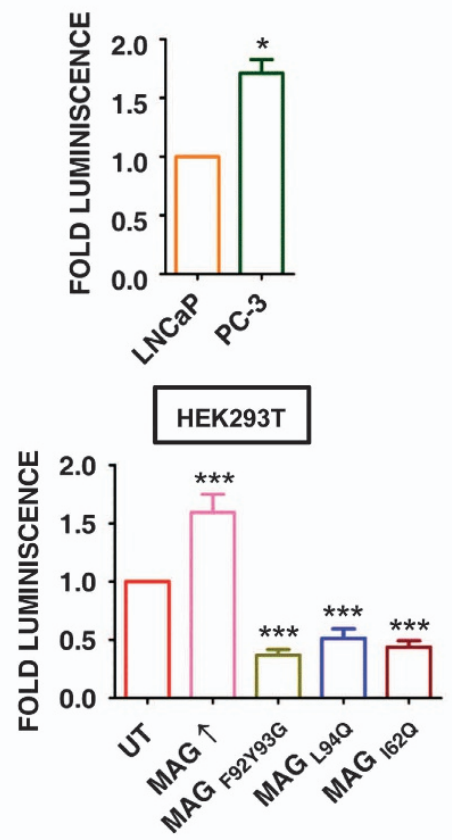

Figure 3 Magmas enhances the activity of respiratory chain complexes for the reduced production of ROS. (a) Mitochondria were isolated from PC-3 and LNCaP cells and subjected to measurement of activities of respiratory chain complexes. (b and $\mathbf{c}$ ) Isolated mitochondria from HEK293T cells overexpressing Magmas (b) and Magmas mutants (c) were utilized for the determination of changes in activities of ETC complexes upon Magmas overexpression and functional defect respectively. All enzyme activities are presented as the rate of the reaction in $\mu \mathrm{M} / \mathrm{s}$. (d) Mitochondrial ATP level was quantified in isolated mitochondria through Promega TOXGlo detection kit. Data represented as mean \pm S.E.M., $n=3 ;{ }^{*} P<0.02$ (two tailed), ${ }^{* \star} P<0.01$ (two tailed) and ${ }^{* * *} P<0.001$ (two tailed) 
had reduced activity of all four ETC complexes as compared with cells overexpressing Magmas. The activities of the ETC complexes were tremendously reduced in case of Magmas mutants. $\mathrm{H}_{2} \mathrm{O}_{2}$-induced oxidative stress causes damage to the complexes leading to decrease in enzymatic activity. The sustained higher complex activity was observed under Magmas overexpression, indicating that Magmas could prevent the damage to the complexes and maintain the cellular metabolism under oxidative stress (Supplementary Figure S5). Thus, it is clear from our findings that Magmas maintains redox equilibrium by both reducing production and promoting scavenging of ROS.

\section{Association of Magmas with elevated enzymatic activity} of antioxidants and mitochondrial DNA copy number. As mitochondrial DNA (mtDNA) encodes some of the core subunits of ETC, we analyzed the amount of mtDNA in cells expressing higher level of Magmas. Staining of isolated mitochondria with SYBr green dye showed enhanced fluorescence in Magmas-overexpressing mitochondria, indicating higher DNA content (Figure 6a). As a second approach, we quantified the mtDNA copy number through quantitative PCR (qPCR) by amplifying two regions of mtDNA, namely $\mathrm{CO} 2$ and ND1 (Figure 6b). Magmas-overexpressing cells showed approximately twofold increase in mtDNA copy number as compared with controls. To conclude, Magmas overexpression leads to enhancement in ETC complex activity possibly by causing an elevation in the mtDNA copy number.

On the other hand, the decrease in ROS under oxidative stress indicates that overexpression of Magmas promotes ROS scavenging. Antioxidants utilize reduced glutathione (GSH) to maintain free radical balance. Hence, the cellular level of reduced and oxidized forms of GSH indicates the involvement of a major antioxidant system, the $\mathrm{GSH} /$ glutathione disulfide (GSSG) cycle. Therefore, we measured the cellular level of reduced and oxidized forms of GSH. Cells overexpressing Magmas showed higher amount of oxidized GSH as compared with controls, whereas the level of GSH remains unchanged (Figures $6 \mathrm{c}$ and $\mathrm{d}$ ). This indicates that the ROS scavenging function of Magmas involves an antioxidant that utilizes GSH in order to prevent oxidative stress. As GPx is a major enzyme that utilizes GSH for the scavenging of peroxides, we measured the activity of GPx. ${ }^{30}$ An elevation in the enzymatic activity of GPx was observed in cells overexpressing Magmas (Figure 6e), thereby preventing the accumulation of ROS under oxidative stress.

Magmas-overexpressing cells, in addition to reduced total ROS, also showed a marked decrease in mitochondrial superoxide. As MnSOD forms the primary enzyme involved in metabolism of superoxides in mitochondria, we measured its activity under elevated Magmas. An increment in MnSOD activity was observed upon overexpression of Magmas under both treated and untreated conditions (Figure 6f). In summary, at the level of ROS scavenging, Magmas increases the activity of MnSOD and GPx, thereby causing a decrease in mitochondrial superoxide level and total cellular ROS level respectively.

Magmas protects damage to biomolecules under oxidative stress. Oxidative stress damages different biomolecules in cellular compartments such as DNA, proteins and lipids. ${ }^{2,31-34}$ One of the critical functions of a ROS regulatory protein is the protection of cellular components by oxidative damage. We detected the capability of Magmas, behaving as a ROS-modulating protein, to rescue the damage to these cellular components in HEK293T cells. Quantification of DNA damage was performed through detection of H2AX phosphorylation. ${ }^{35}$ We observed that Magmas-overexpressing cells scored least DNA damage as compared with control cells after exposure to $\mathrm{NaAsO}_{2}$ (Figures $7 \mathrm{a}$ and b). Contrastingly, in cells expressing Magmas mutants, the damage to DNA was found to be comparatively higher even in the absence of oxidative stress (Figure 7c). Cells treated with $5 \mu \mathrm{M}$ cisplatin or $500 \mu \mathrm{M} \mathrm{CuSO}_{4}$ was used as positive control. Similarly, cells overexpressing Magmas showed a lesser amount of lipid peroxidation as compared with control upon treatment with $\mathrm{NaAsO}_{2}$, and mutants showed a significant extent of lipid peroxidation even under untreated condition (Figure 8a). The detrimental effect of enhanced mitochondrial ROS on Fe-S cluster proteins, in Magmas mutants was analyzed by measuring the activity of Fe-S enzyme aconitase. We found that Magmas mutants had a significant decrease in aconitase activity (Figure 8b). Similarly, Magmas mutants cause higher level of protein carbonylation that was further enhanced with increased ROS under treated condition. However, elevated level of Magmas prevented accumulation of carbonylated forms of proteins in the cell even under oxidative insult (Figure $8 c$ ). Similar cytoprotective role of Magmas under oxidative stress was observed in yeast cells (Supplementary Figure S6).

\section{Discussion}

Magmas was originally identified as protein involved in GM-CSF signaling ${ }^{21}$ and was later found to be a part of mitochondrial import machinery where it functions as a cochaperone of $\mathrm{mtHsp} 70 .^{22}$ Magmas forms a subcomplex with DnaJC19 and DnaJC15 and regulates the ATPase activity of mtHsp70, thereby aiding the import of precursor proteins into the mitochondrial matrix. ${ }^{22,36-38}$ Magmas-like protein is associated with plant survival and regulates plant immunity. ${ }^{39}$ Upregulation of Magmas has been found in metabolically active tissues, various carcinomas and in tissues of different developmental stages, but the physiological relevance of such higher levels of the protein is still unknown. Through our study, we propose that enhanced expression level of Magmas is important for its function as a ROS modulator. It is clear from our study that overexpression of Magmas in HEK293T and prostate carcinoma cell line resulted in a decrease in ROS, whereas the cells with a lower amount of protein had elevated oxidative stress. Similarly, yeast cells expressing a lower amount of Magmas were not able to withstand the stress condition but cells with an enhanced level of Magmas were more tolerant to ROS. The ROS regulatory function of Magmas is exclusive of its role in the import of precursor proteins inside the mitochondria. It is evident from our results that reduction of Magmas level in PC-3 cells does not result in an import defect, but leads to accumulation of cellular ROS. Similarly, an elevation of ROS was observed in Magmas mutants expressing yeast cells 
grown at the permissive temperature that results in protein import comparable to wild type. ${ }^{22}$ In summary, Magmas by virtue of its overexpression acts as a ROS regulator to maintain cellular redox homeostasis and its ROS modulatory function is independent of its function in the import of precursor proteins.
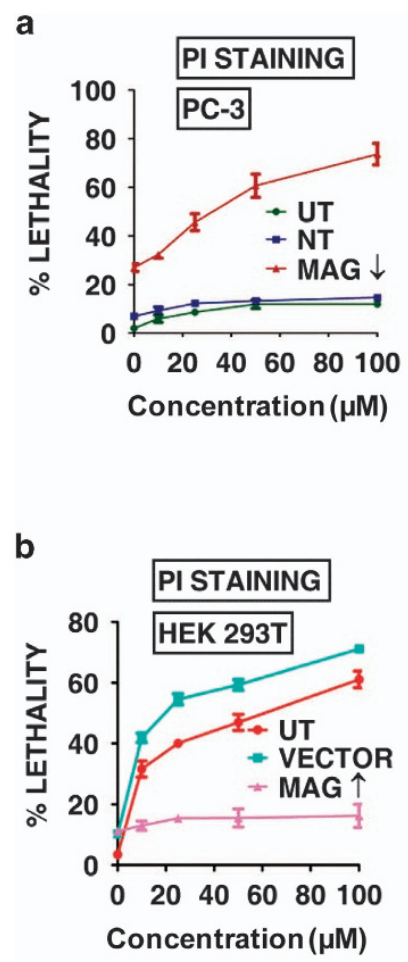

g
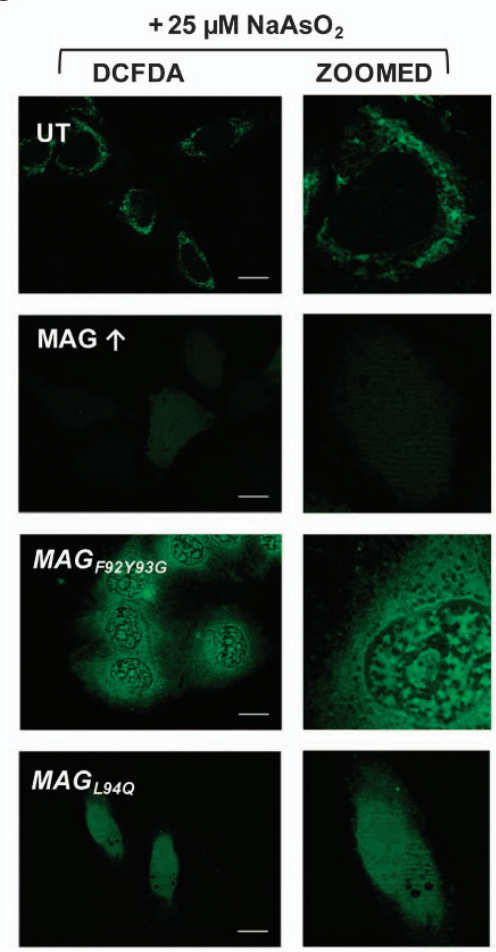

c

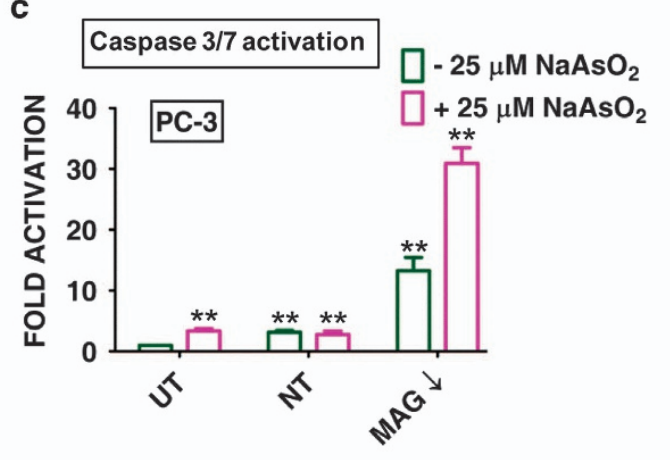

d

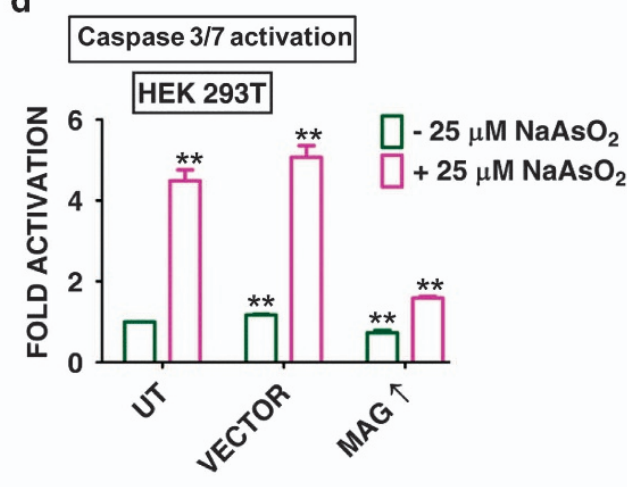

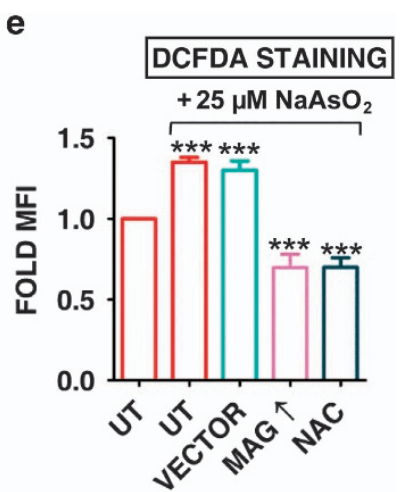

f

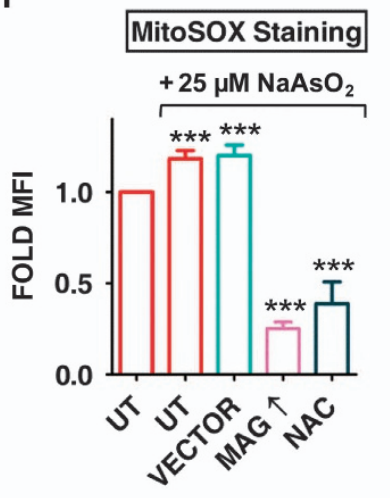

h
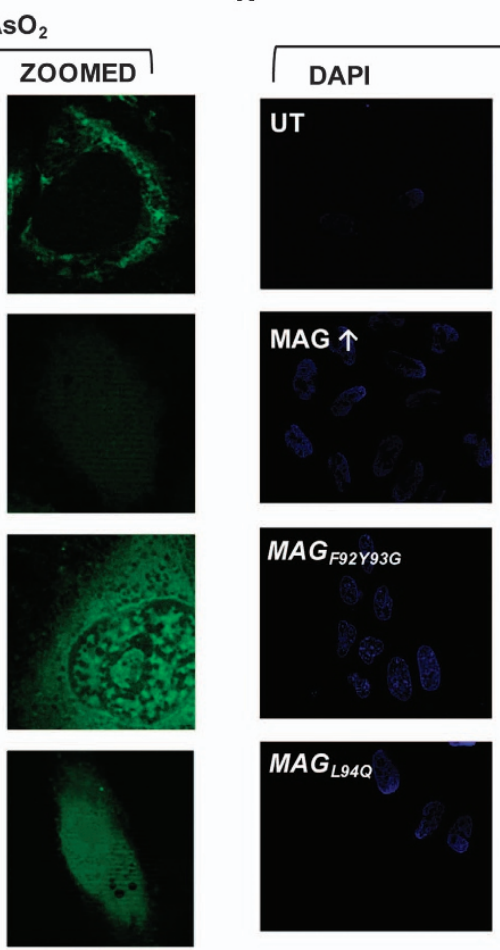

$+25 \mu \mathrm{M} \mathrm{NaAsO}$
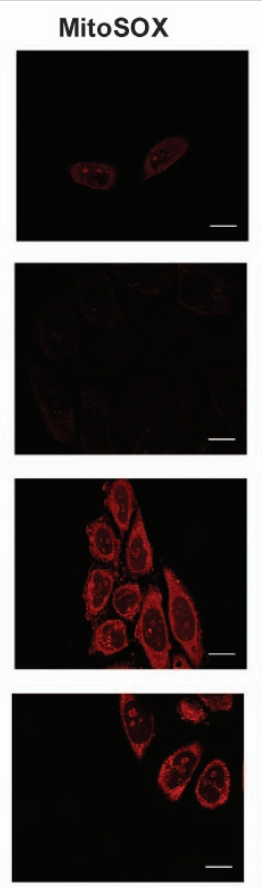
ZOOMED
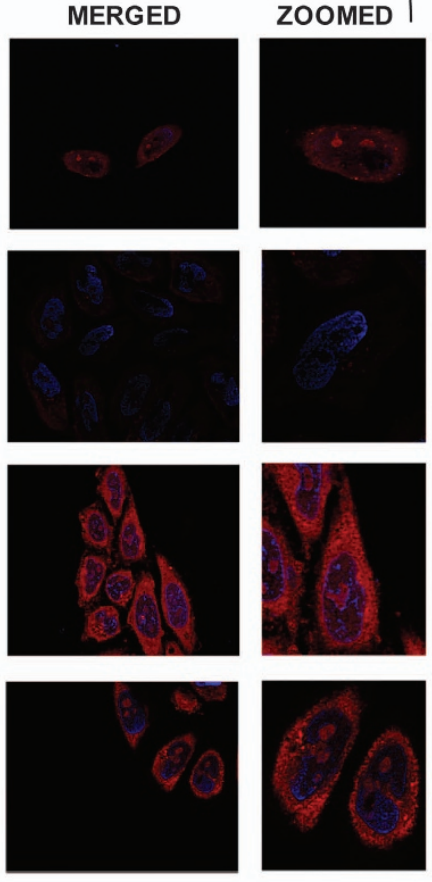
The intriguing question arises of how Magmas can maintain the redox equilibrium. Redox balance can be maintained either by regulating ROS scavenging or production. ROS is mostly generated in mitochondria by the slippage of electrons from the electron carriers of ETC. ${ }^{40}$ Better enzymatic activity of ETC complexes causes proper channeling of electrons through different carriers and prevents their leakage, resulting in decreased ROS production. ${ }^{3,27}$ Magmas modulates ETC complex activity both in the presence and absence of oxidative stress and protects the complexes from ROSinduced damage. The proper channeling and lesser leakage of electrons promotes oxidative phosphorylation leading to enhanced ATP production. Our study reveals that a significant elevation of ATP level occurs upon Magmas overexpression because of increased ETC complex activity, thus reducing the production of ROS. This highlights that Magmas plays a crucial role in redox maintenance. Oxidative stress is one of the intervening factors of neurodegenerative disorders. Indeed, impairment of ETC complex activity due to oxidative damage is found to be associated with Parkinson's disease. ${ }^{41}$ At the molecular level, it is conceivable that Magmas might be inhibiting J-protein, DnaJC15 function, that is known to interact with ETC complexes and regulate their activity. ${ }^{42}$ In line with this idea, mutations in Magmas J-like domain that disrupts the interaction between the J-proteins ${ }^{22}$ are associated with lower ETC complex activity coupled with enhanced ROS. On the other hand, the capability of Magmas to prevent accumulation of ROS under the condition of induced oxidative stress suggests that Magmas promotes ROS scavenging under overexpressed condition. Indeed, HEK293T and yeast cells with a lower expression level of Magmas accumulate significant ROS after an exposure to exogenous oxidative stress. Our results suggest that the ROS scavenging potential of Magmas-overexpressing cells is due to the elevated enzymatic activities of two major antioxidants, GPx and MnSOD, both in the presence and absence of oxidative stress. Hence, present findings clearly suggest that Magmas overexpression has a critical role in maintaining ROS level at both production and scavenging levels (Supplementary Figure S7).

Elevated ROS levels are commonly observed in neuronal cells, as the metabolism of many neurotransmitters provides an additional source of free radical generation, necessitating the maintenance of redox homeostasis. ${ }^{43,44}$ As reported earlier, cells from neuronal origin express higher level of Magmas as compared with cells of other origins, ${ }^{28}$ underlying the role of Magmas as a potential ROS modulator in these cells. Similarly, higher expression of Magmas found in metabolically active tissues is beneficiary to these cells that are more susceptible to ROS production because of high rate of respiration.

By maintaining the redox equilibrium, ROS regulatory proteins provide protection to cellular components against oxidative damage. Our results clearly indicate the cytoprotective role of Magmas that was found to protect all the major biomolecules, lipids, DNA and protein, from oxidative damage. Prevention of oxidative modifications to proteins by Magmas might thwart the formation of protein aggregates that are associated with neurodegenerative disorders. ${ }^{45,46}$ Similarly, peroxidation of lipids that is associated with atherosclerosis, diabetes and neurodegeneration was also prevented by Magmas. ${ }^{47}$ Finally, Magmas impedes the damage to nucleic acids, thus preventing accumulation of mutations. Our observations suggest that by reducing ROS level and preventing the damage to cellular components, Magmas prevents ROS-mediated activation of caspases required for apoptotic cell death. This circumvention from apoptosis and maintenance of survivability under stress condition holds especial importance for cancer cells. ${ }^{48}$ Being exposed to an elevated level of ROS, cancer cells have to evolve an efficient mechanism to escape the probability of ROS-mediated apoptotic cell death. Indeed, enhanced level of Magmas has been reported in many carcinomas such as prostate, pituitary and multiple myeloma. ${ }^{21}$ Thus, it can be concluded that Magmas maintains the sublethal level of ROS and promotes 'redox adaptation' in cancer cells.

In summary, the optimum level of cellular ROS is required for the balanced redox homeostasis and is maintained by the help of ROS modulatory proteins. Redox homeostasis in higher eukaryotes is more complex from that of the lower eukaryotes because of diversified external environment. ${ }^{49}$ This variegation provides the basis for the evolution of proteins to perform ROS regulatory function. In this study, we propose that Magmas, traditionally regarded as a cochaperone of $\mathrm{mtHsp} 70$, has evolved to perform an additional function as ROS regulator in higher eukaryotes. The identification of novel cytoprotective ROS modulators such as Magmas holds special importance toward its prospective future implication in understanding the different pathophysiological conditions associated with oxidative stress.

\section{Materials and Methods}

Cell culture and cloning. HEK293T cells were cultured in advanced Dulbecco's modified Eagle's medium (DMEM; Invitrogen, Carlsbad, CA, USA) containing $10 \%$ fetal bovine serum (Gibco, Carlsbad, CA, USA) and $1 \%$ penicillinstreptomycin (Gibco) at $37^{\circ} \mathrm{C}$ in $5 \% \mathrm{CO}_{2}$. To culture PC-3, DMEM/F12 (Invitrogen)

Figure 4 Magmas prevents accumulation of ROS under conditions of oxidative stress. (a) Magmas was downregulated in PC-3 (Mag $\downarrow$ ) cells followed by an exposure to increasing concentration of $\mathrm{NaAsO}_{2}(10-100 \mu \mathrm{M})$ for $90 \mathrm{~min}$. The increment in lethality was assessed by cellular uptake of PI. (b) Untransfected HEK293T cells (UT), cells transfected with empty vector and HEK293T cells overexpressing Magmas (Mag $\uparrow$ ) were treated with increasing concentrations of $\mathrm{NaAsO}_{2}$ for 90 min and the cellular viability was estimated by PI staining and represented in terms of percentage lethality with increasing oxidative stress. (c and d) Activation of caspase 3 and 7 was measured by ApoGlo kit from Promega. PC-3 cells with downregulation of Magmas (c) and HEK293T cells with overexpression of Magmas (d) were treated with $25 \mu \mathrm{M} \mathrm{NaAsO}{ }_{2}$, and the activation of caspases was detected by fluorescence generated through the cleavage of substrate. (e) HEK293T cells with higher expression of Magmas were exposed to oxidative stress $\left(25 \mu \mathrm{M} \mathrm{NaAsO}_{2}\right)$ and stained with DCFDA dye, and the level of cellular ROS was depicted as fold MFI over the untransfected untreated HEK293T cell. (f) After treatment with $25 \mu \mathrm{M} \mathrm{NaAsO}_{2}, \mathrm{HEK} 293 \mathrm{~T}$ cells with enhanced expression of Magmas were subjected for measurement of the level of mitochondrial superoxides. The cells were stained with MitoSOX and superoxide level was presented as fold MFI over untransfected untreated HEK293T cells as was analyzed through flow cytometry. As a control for reduction of ROS, cells were recovered with $2 \mathrm{mM} \mathrm{N}$-acetyl cysteine (NAC) for $1 \mathrm{~h}$ after $\mathrm{NaAsO}_{2}$ treatment. Data represented as mean $\pm \mathrm{S}$. E.M., $n=3$; ${ }^{\star *} P<0.05$ (two tailed) and ${ }^{* *} P<0.0001$ (two tailed). ( $\mathbf{g}$ and $\mathbf{h}$ ) To validate the ROS modulating property of Magmas, HeLa cells overexpressing Magmas and Magmas mutants were subjected to $25 \mu \mathrm{M} \mathrm{NaAsO}_{2}$ treatment followed by staining with DCFDA dye (g) and MitoSOX (h). The fluorescent intensity of the oxidized dye was observed through microscopy. Scale bar: $10 \mu \mathrm{m}$ 
a
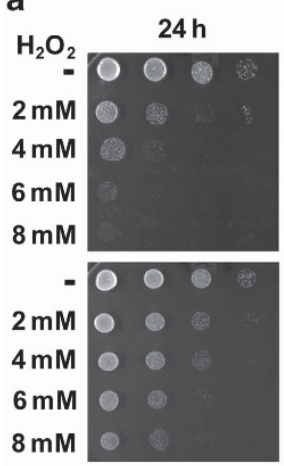

$27 \mathrm{~h}$
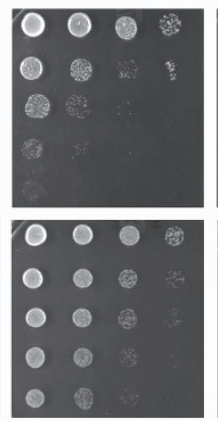

$36 \mathrm{~h}$
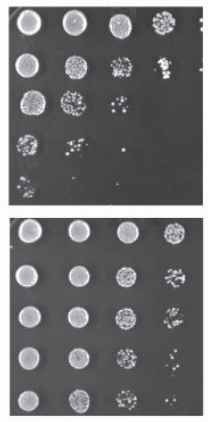

$48 \mathrm{~h}$

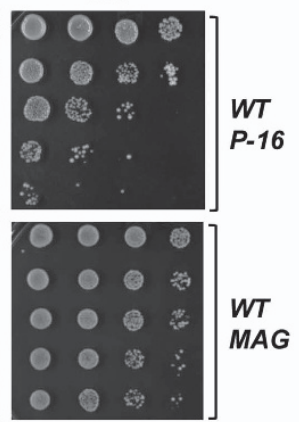

b

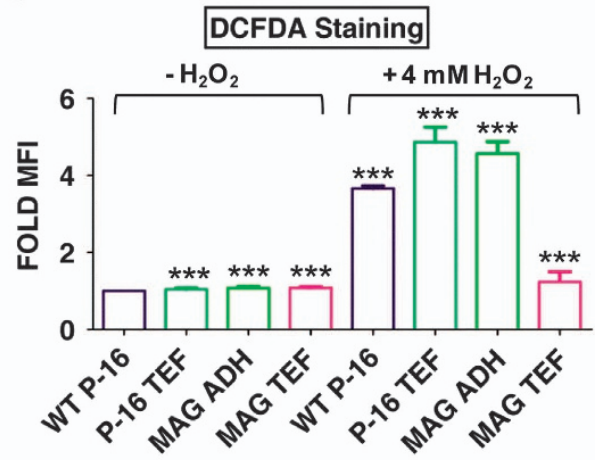

C

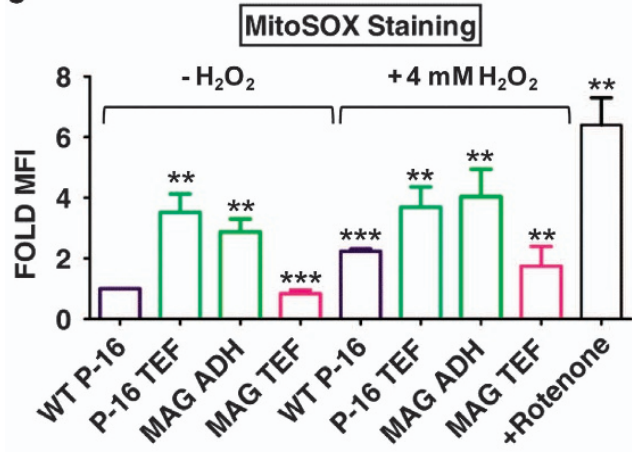

d

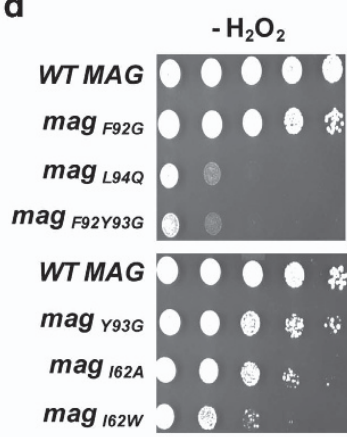

$+\mathrm{H}_{2} \mathrm{O}_{2}$
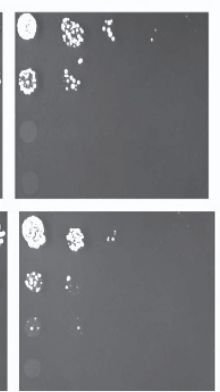

e
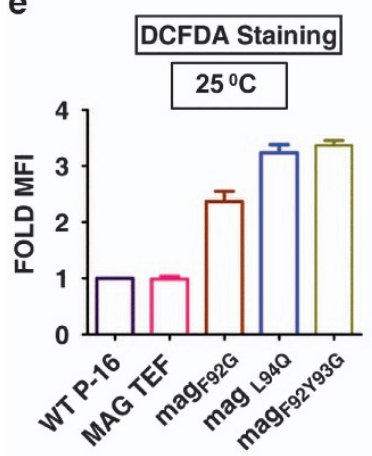

f

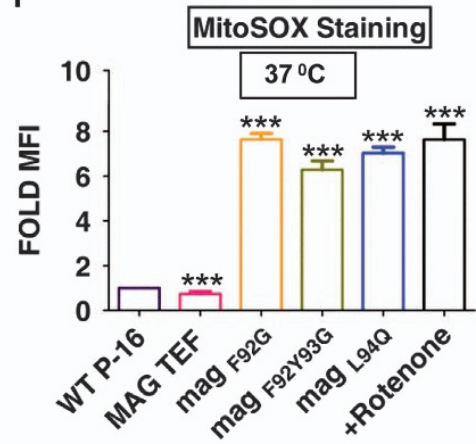

g

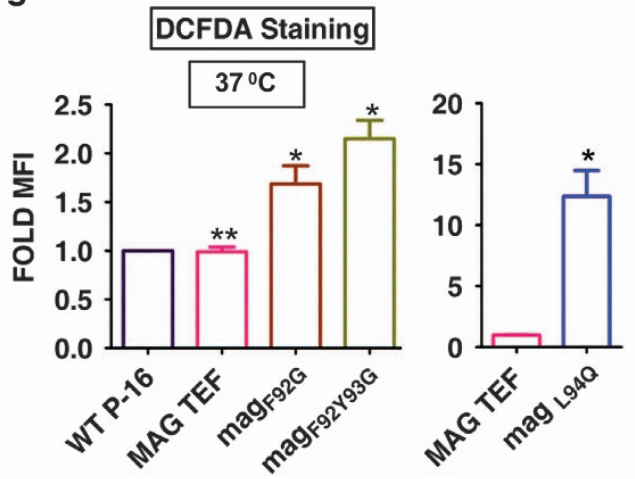

Figure 5 Conserved function of Magmas as ROS modulator in lower eukaryotes: involvement of J-like domain. Magmas was expressed under $A D H$ and TEF promoter in yeast cells deleted for wt PAM16 (P-16), (a) Yeast cells expressing wt P-16 and Magmas were pretreated with increasing concentrations of $\mathrm{H}_{2} \mathrm{O}_{2}(2-8 \mathrm{mM})$ followed by spotting over YPD medium for recovery at $30^{\circ} \mathrm{C}$ for different time intervals as indicated. (b and $\mathbf{c}$ ) Yeast strains expressing different levels of Magmas and P-16 were subjected to oxidative stress by peroxide treatment and then stained with DCFDA (b) and MitoSOX (c). The cellular level of ROS and mitochondrial superoxide level were presented in the form of fold MFI of respective dyes over the untreated wt P-16 as analyzed by flow cytometry. (d) The ability of Magmas mutants to survive under oxidative stress was analyzed by their ability to recover after an exposure of peroxide. (e) DCFDA staining of mutant expressing yeast cells grown at $25^{\circ} \mathrm{C}$ (permissive temperature). (f and $\mathbf{g}$ ) Mutant strains were revived at $25^{\circ} \mathrm{C}$ followed by a heat shock at $37^{\circ} \mathrm{C}$ (nonpermissive temperature) for $2 \mathrm{~h}$ to generate a mutant phenotype before staining with MitoSOX (f) and DCFDA (g) that were analyzed by flow cytometry to measure ROS level. Data represented as mean \pm S.E.M.; $n=3 ;{ }^{*} P<0.01$ (two tailed), ${ }^{* *} P<0.001$ (two tailed) and ${ }^{* \star \star} P<0.0001$ (two tailed)

and, for LNCaP, RPMI-1640 (Invitrogen) with 10\% serum and 1\% Glutamax and Penstrep were used as medium. Gene encoding Magmas with a C-terminus HA tag was cloned in plasmid pCDNA3.1a. HEK293T cells were transfected with a construct of Magmas in pCDNA3.1a by using Lipofectamine 2000 (Invitrogen). Magmas mutants were cloned in pCl-neo vector and transfected in HEK293T cells to generate a semidomiant negative phenotype. Cells expressing Magmas and Magmas mutants were harvested for different experiments after $48 \mathrm{~h}$ of transfection.

Yeast strains and cloning. MAGMAS was cloned in pRS415 vector under TEF promoter and in pRS414 vector under $A D H$ promoter for its differential expression. Pam16 and Magmas mutants were cloned in pRS415 TEF. The constructs containing cDNA encoding for Magmas and Pam16 were transformed in
Spam16 haploid yeast cells containing wild-type PAM16 in a URA3-based plasmid. The transformants were selected on minimal medium and streaked on 5-FOA plates to select for cells having lost the URA3 plasmid. The generated strains expressing wildtype and mutant Magmas were revived on YPD medium before assays. All genetic analyses were performed in PJ53 background strain of Saccharomyces cerevisiae.

Measurement of ROS. The total cellular ROS level was measured using DCFDA dye, and for mitochondrial superoxide detection, MitoSOX Red was used. For the detection of ROS in human cells, 50000 cells were stained with $15 \mu \mathrm{M}$ DCFDA for $15 \mathrm{~min}$ at $37^{\circ} \mathrm{C}$. The cells were washed with $1 \times$ phosphate buffer saline (PBS) and subjected to a flow cytometric analysis at excitation wavelength of $492 \mathrm{~nm}$ and emission of $520 \mathrm{~nm}$ using BD FACSCanto II flow cytometer 
a
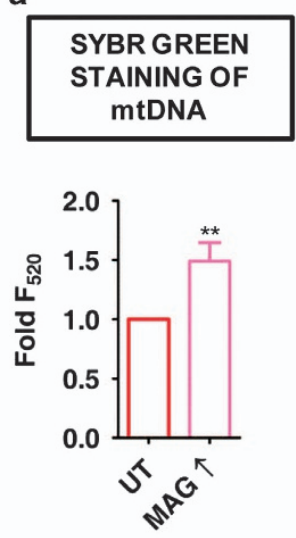

d

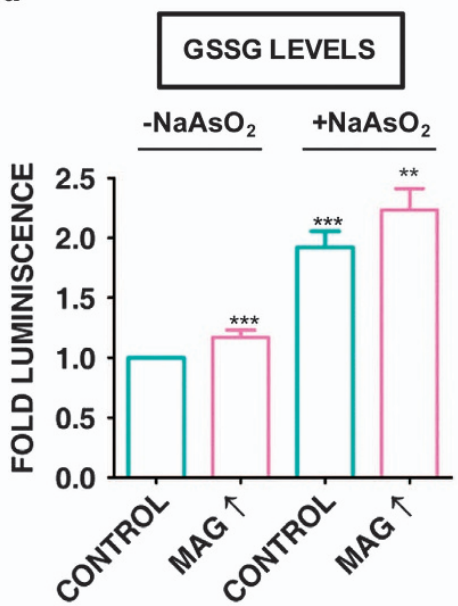

b

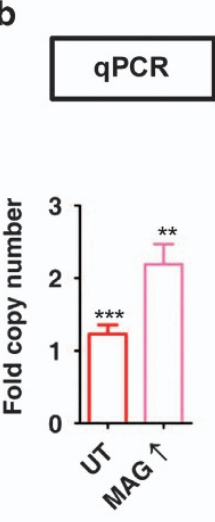

c

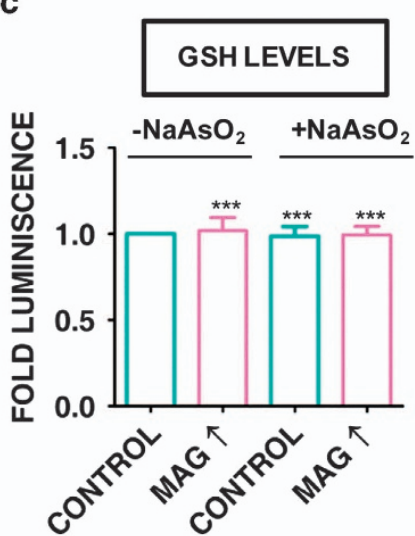

e

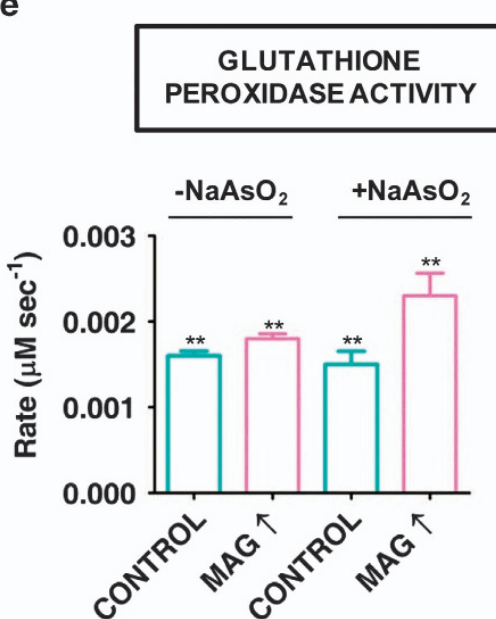

f

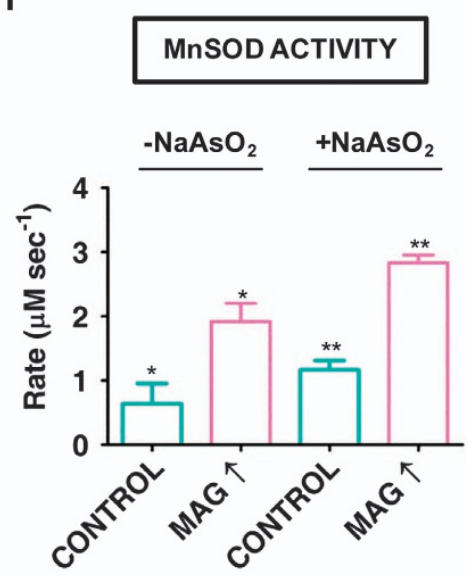

Figure 6 Overexpression of Magmas is associated with elevated enzymatic activity of antioxidants and mitochondrial DNA copy number. (a) For the quantitative measurement of mtDNA, isolated mitochondria expressing a basal level of Magmas (UT) and higher amount of protein (Mag $\uparrow$ ) were stained with SYBr green and the fluorescence emitted upon its binding to mtDNA was represented as fold fluorescent at $520 \mathrm{~nm}\left(\mathrm{~F}_{520}\right)$ over the control (UT). (b) To quantify the mtDNA copy number, two regions of mtDNA, namely ND1 and CO2, were amplified by qPCR and data are presented as fold change in the copy number upon Magmas overexpression over untransfected control. (c and d) Level of cellular GSH (c) and GSSG (d) was measured in cells overexpressing Magmas in a luminescence-based assay in the presence or absence of oxidative stress. (e) The enzyme activity of glutathione peroxidase was measured spectrophotometrically under untreated condition and after treatment of $25 \mu \mathrm{M}$ $\mathrm{NaAsO}_{2}$. (f) Isolated mitochondria were utilized to measure the activity of MnSOD upon Magmas overexpression. The activity is presented in terms of rate of the reaction. Data represented as mean \pm S.E.M., $n=3 ;{ }^{*} P<0.01$ (two tailed), ${ }^{* *} P<0.001$ (two tailed) and ${ }^{* \star *} P<0.0001$ (two tailed)

(San Jose, CA, USA). For MitoSOX staining, 50000 cells were harvested and stained with $5 \mu \mathrm{M}$ dye for $10 \mathrm{~min}$ at $37^{\circ} \mathrm{C}$. The stained cells were excited at $510 \mathrm{~nm}$ and the emitted fluorescence was detected at $580 \mathrm{~nm}$ by flow cytometry.

ROS in yeast cells was quantified after growing them in $\mathrm{YPD}$ medium at $30^{\circ} \mathrm{C}$ to late log phase. Next, $0.3 \mathrm{OD}$ of cells were harvested and stained with $50 \mu \mathrm{M} \mathrm{DCFDA}$ for $15 \mathrm{~min}$ at $30^{\circ} \mathrm{C}$ for flow cytometric analysis. Mitochondrial superoxides were detected by adding $5 \mu \mathrm{M}$ MitoSOX dye to $0.3 \mathrm{OD}$ of cells followed by incubation at $30^{\circ} \mathrm{C}$ for $15 \mathrm{~min}$. To expose the cells to oxidative stress, yeast cells were treated with $4 \mathrm{mM} \mathrm{H}_{2} \mathrm{O}_{2}$ for $3 \mathrm{~h}$ and $30 \mathrm{~min}$ at $30^{\circ} \mathrm{C}$. Human cells were treated with $25 \mu \mathrm{M}$ $\mathrm{NaAsO}_{2}$ for $90 \mathrm{~min}$ at $37^{\circ} \mathrm{C}$ to induce oxidative stress before the detection of ROS.

The formation of peroxides in cell was validated by Amplex Red Hydrogen Peroxide/Peroxidase Assay Kit (Invitrogen Molecular Probes, Eugene, OR, USA) and fluorescence was observed at $585 \mathrm{~nm}$.

siRNA transfection. For the downregulation of Magmas in HEK293T cells, a pool of dsiRNA (IDT HSC.RNAi.NO16069.12.1 and IDT HSC.RNAi.NO16069.12.2) was transfected using Lipofectamine 2000 and cells were harvested after $48 \mathrm{~h}$ of transfection. Magmas was downregulated in PC-3 cells through Lipofectamine-based transfection of dsiRNA and the cells were harvested after $24 \mathrm{~h}$ of transfection. Nontargeting dsiRNA was used as a negative control for siRNA-mediated downregulations.
Western blotting. The expression level of Magmas was semiquantitatively measured through western blotting. Based on Bradford test, $100 \mu \mathrm{g}$ protein corresponding to mitochondria was loaded on SDS-PAGE and transferred to PVDF membrane. Protein was probed with anti-Magmas or anti-Pam16 antibody for $1 \mathrm{~h}$ at room temperature. HRP-conjugated anti-rabbit secondary antibody was used for its detection. Anti-Tim23 antibody was used as loading control of mitochondria-enriched fractions. As a loading control in detection of protein expression in yeast, anti-Mge1 and anti-Tim50 antibodies were used.

Isolation of mitochondria. HEK293T, PC-3 and LNCaP cells were grown upto $90 \%$ confluency in DMEM, DMEM/F12 and RPMI- 1640 , respectively, at $37^{\circ} \mathrm{C}$ in $5 \% \mathrm{CO}_{2}$. Cells were harvested with the help of $0.25 \%$ Trypsin-EDTA and washed with $1 \times$ PBS. Cells were incubated in hypotonic solution $(10 \mathrm{mM}$ Tris, $10 \mathrm{mM} \mathrm{NaCl}, 3 \mathrm{mM} \mathrm{MgCl}, 1 \mathrm{mM}$ EDTA) for $30 \mathrm{~min}$ in the presence of protease inhibitor followed by homogenization. Mitochondria-enriched fraction was isolated by differential centrifugation. Mitochondria were isolated from exponentially dividing yeast cells as described by Liu et al. ${ }^{50}$

Caspase $3 / 7$ activation. Activation of caspases was detected using Promega Apo-ONE Homogeneous Caspase-3/7 assay kit (Promega, Madison, WI, USA). 
a
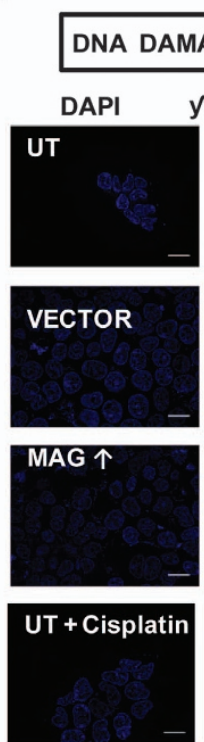
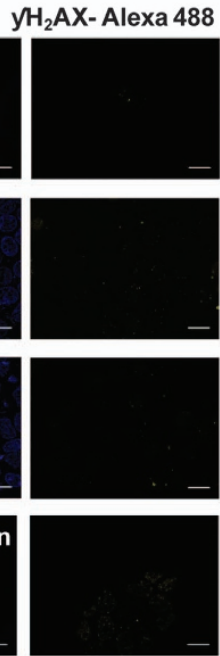

MERGED
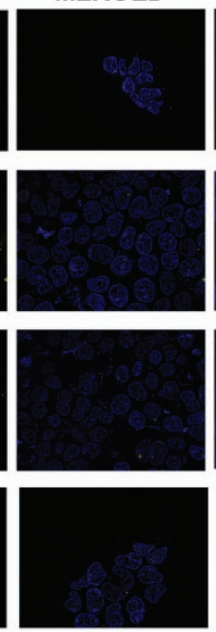

ZOOM
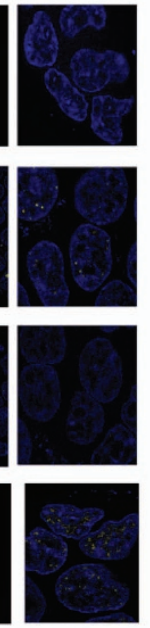

b

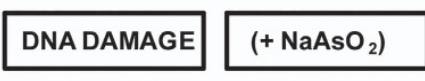

DAPI $\mathrm{yH}_{2} \mathrm{AX}$-Alexa 488 MERGED

ZOOM
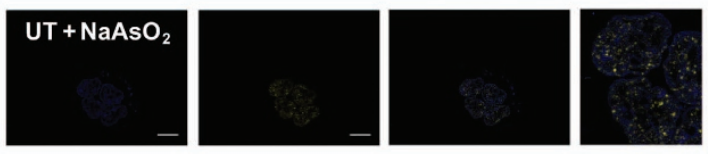

VECTOR +

$\mathrm{NaAsO}_{2}$
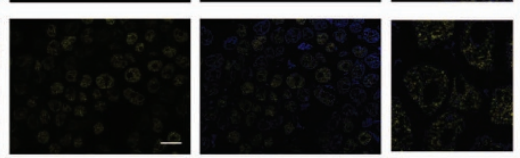

MAG $\uparrow+$

$\mathrm{NaAsO}_{2}$
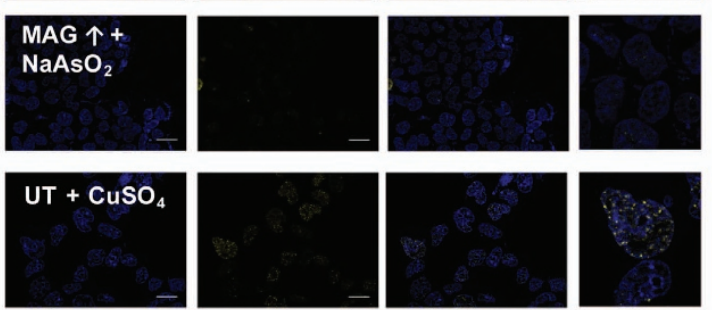

c

DNA DAMAGE IN MAGMAS MUTANTS WITHOUT EXTERNAL STRESS
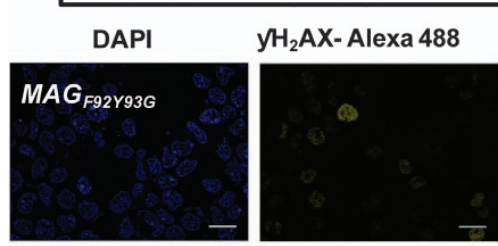

MERGED

ZOOM
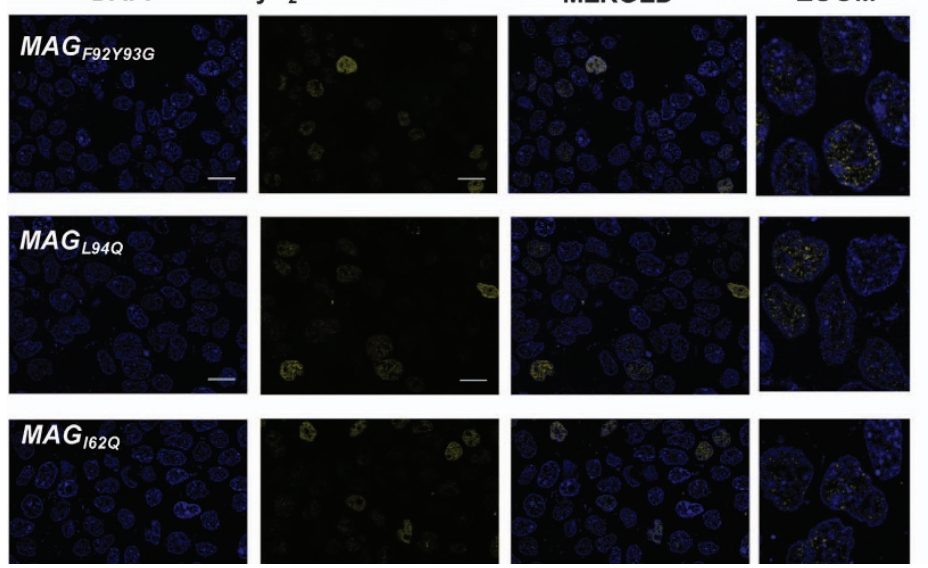

Figure 7 Magmas prevents oxidative stress-mediated DNA damage. Magmas rescues damage to the cellular components such as nucleic acid, lipid and protein caused by enhanced ROS levels. (a) Damage to DNA was assessed by antibody-mediated detection of phosphorylation of H2AX at S-139 as a response to double-stranded breaks. HEK293T cells overexpressing Magmas were lysed and probed with anti- $\gamma \mathrm{H} 2 \mathrm{AX}$ antibody, followed by incubation of secondary antibody conjugated with Alexa-488, and the foci formed were detected by fluorescence microscopy. Foci observed to correspond to the double-stranded breaks in DNA. As positive control, $5 \mathrm{mM}$ cisplatin was used. (b) HEK293T cells with Magmas overexpression were treated with $25 \mu \mathrm{M} \mathrm{NaAsO}_{2}$ to induce oxidative stress-mediated DNA damage. Double-strand break formation under oxidative stress was analyzed through immunofluorescence by anti- $\gamma \mathrm{H} 2 \mathrm{AX}$ antibody. Treatment with $500 \mu \mathrm{M} \mathrm{CuSO}_{4}$ was used as a positive control for ROS-mediated DNA damage. (c) Detection of $\gamma \mathrm{H} 2 \mathrm{AX}$ foci in HEK293T cells expressing Magmas mutants in the absence of exogenous stress. Scale bar: $10 \mu \mathrm{m}$

Drop dilution analysis. Yeast cells expressing wild-type Pam16 and Magmas under TEF promoter were grown at $30^{\circ} \mathrm{C}$ to the late log phase. Next, 0.5 $\mathrm{OD}$ of cells were harvested and pretreated with different concentrations of $\mathrm{H}_{2} \mathrm{O}_{2}$ for $3 \mathrm{~h} 30 \mathrm{~min}$ at $30^{\circ} \mathrm{C}$ followed by spotting on YPD medium for recovery. Growth of the cells exposed to the oxidative stress was observed at different time intervals as indicated. Strains expressing Magmas mutants were revived at permissive temperature and pretreated with $4 \mathrm{mM} \mathrm{H}_{2} \mathrm{O}_{2}$. The ability of mutants to withstand the oxidative insult was assessed by recovering them on YPD.

Cell imaging. HeLa cells (cell count 5000) were grown in DMEM at $37^{\circ} \mathrm{C}$ with $5 \% \mathrm{CO}_{2}$. At $48 \mathrm{~h}$ before imaging, cells were transfected with Magmas and Magmas mutants and grown in DMEM. Cells were stained with $3 \mu \mathrm{M}$ DCFDA for $10 \mathrm{~min}$, and mounted in ProLong Gold Antifade reagent (Invitrogen) or in phenol red-free DMEM before imaging. To measure mitochondrial superoxides, cells overexpressing Magmas and Magmas mutants were stained with $25 \mu \mathrm{M}$ MitoSOX for $15 \mathrm{~min}$ and mounted in ProLong Gold Antifade reagent with DAPI (Invitrogen). All images were analyzed under Zeiss AxioObserver Z1 Apotome 2.0 (Jena, Germany) $63 \times$ oil NA 1.45. Images were acquired using Zeiss AxioCam MRm Camera (Jena, Germany) at constant exposure of $300 \mathrm{~ms}$ and processed using Zeiss Axio vision Rel. 4.8 software (Jena, Germany). Images were zoomed digitally by Adobe Photoshop CS4 (San Jose, CA, USA). The images were quantified by selecting a uniform area to measure the change in fluorescent intensity of respective dyes, using ImageJ software (National Institute of Health, Bethesda, MD, USA).

Measurement of mitochondrial ATP levels. The level of ATP was measured in isolated mitochondria by Promega TOX Glo detection kit (Promega). 
a

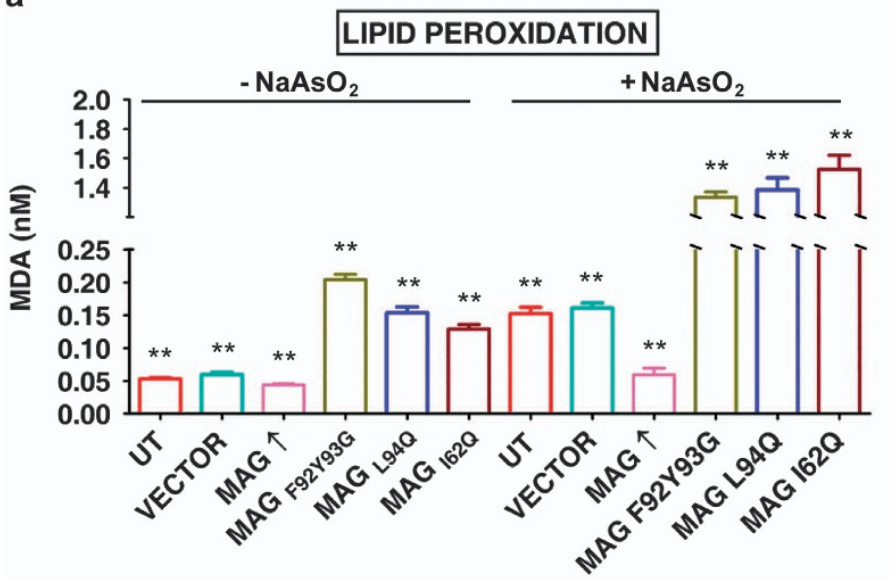

b

\section{ACONITASE ACTIVITY}

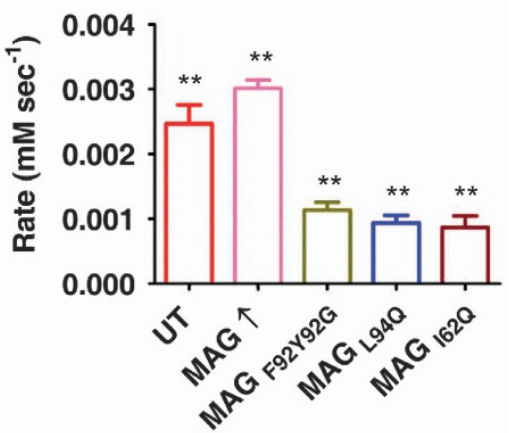

c

\section{PROTEIN CARBONYLATION}

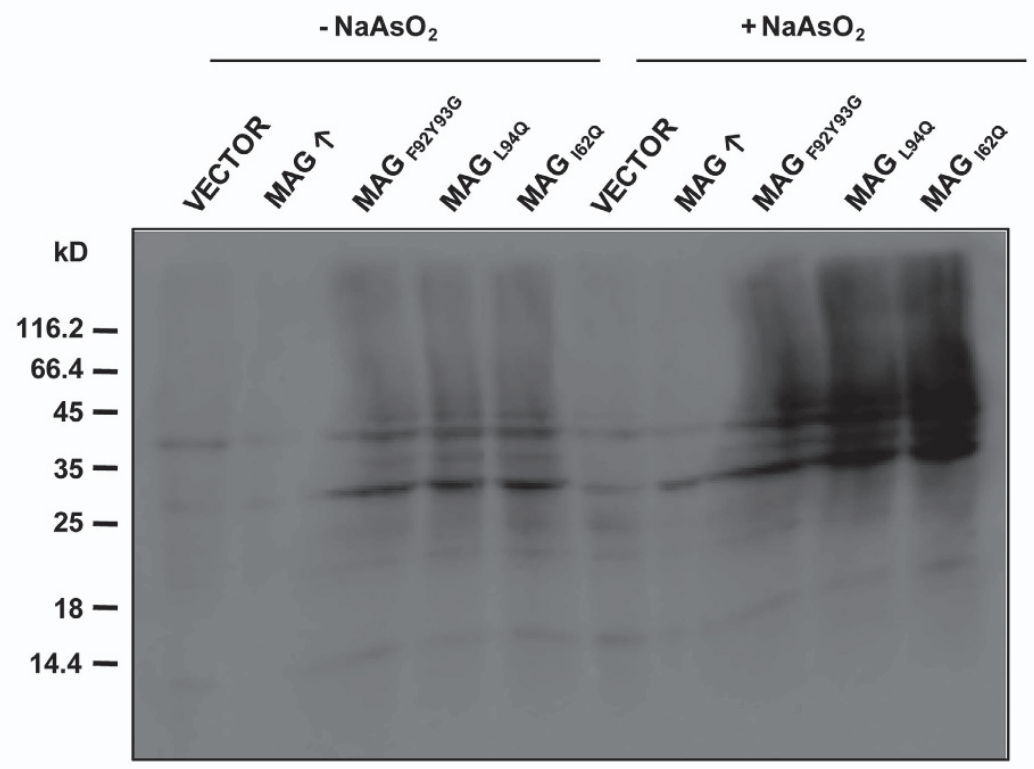

Anti-ß actin

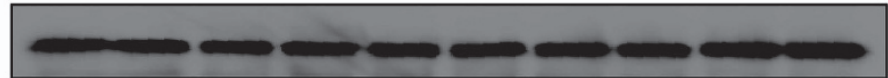

Figure 8 Physiological relevance of maintenance of REDOX equilibrium by Magmas: protection to lipid and protein. (a) ROS-mediated oxidation of lipid in cells exposed to oxidative stress was detected by TBARS assay via spectrophotometric detection of its end product malondialdehyde at $532 \mathrm{~nm}$. (b) The damage to Fe-S cluster leads to the loss of enzyme activity. To determine the oxidative damage to Fe-S cluster in Magmas mutant-expressing cells, aconitase activity was measured in isolated mitochondria. (c) The oxidative damage to the protein leads to carbonylation of its residues. The extent of protein carbonylation was analyzed by the reaction of carbonyl groups with 2,4-dinitrophenylhydrazine (DNPH). The derivatization of protein carbonyls to 2,4-dinitrophenylhydrazone (DNP) was analyzed by using an anti-DNP antibody. Anti- $\beta$-actin antibody was used as loading control. Data represented as mean $\pm S$.E.M., $n=3$; ${ }^{* \star} P<0.001$ (two tailed)

Protein carbonylation. The extent of protein carbonylation was assessed by OxyBlot Protein Oxidation Detection kit (Millipore, Billerica, MA, USA). Procedure followed as directed by the instructions of the manufacturer. Briefly, cells were lysed for the preparation of protein extract. Then, $5 \mu \mathrm{g}$ protein was derivatized to 2,4-dinitrophenylhydrazone (DNP). DNP was detected using an antiDNP antibody through immunoblotting.

PI staining. Cells were treated with increasing concentrations of $\mathrm{NaAsO}_{2}$ $(10,25,50$ and $100 \mu \mathrm{M})$ for $90 \mathrm{~min}$ at $37^{\circ} \mathrm{C}$ to induce generation of ROS. Cells were harvested by using $0.25 \%$ Trypsin-EDTA and stained with $0.8 \mu \mathrm{g}$ of dye just before analyzing through flow cytometry.
NAO staining. A total of 50000 cells were stained with $10 \mathrm{nM}$ NAO (Invitrogen Molecular Probes) and fluorescence was measured flow cytometrically at $530 \mathrm{~nm}$.

Measurement of ETC complex activity. Activity of ETC complexes was quantified based on the protocol described by Spinazzi et al..$^{51}$ For the detection of complex I activity, mitochondria were incubated in phosphate buffer containing $1 \%$ DOC and $2 \mathrm{mM}$ sodium azide for $15 \mathrm{~min}$ on ice. Permeabilized mitochondria were then incubated with $1 \mathrm{mM} \mathrm{NADH}$, and the reaction was initiated with the addition of $60 \mu \mathrm{M}$ ubiquinone. The decrease in absorbance by the oxidation of NADH was recorded at $340 \mathrm{~nm}$ for $2 \mathrm{~min}$. Complex II activity was measured in a coupled assay. Mitochondria were incubated with $20 \mathrm{mM}$ succinate in a phosphate 
buffer for $10 \mathrm{~min}$ at $30^{\circ} \mathrm{C}$ to activate complex II. Then, $2 \mu \mathrm{g} / \mu \mathrm{l}$ rotenone, $2 \mu \mathrm{g} / \mu \mathrm{l}$ antimycin and $2 \mathrm{mM}$ sodium azide were added to inhibit other complexes. After addition of $65 \mu \mathrm{M}$ ubiquinone, the reduction of ubiquinone was linked to the reduction of DCPIP $(50 \mu \mathrm{M})$. The production of colorless reduced DCPIP was measured as a decrease in absorbance at $600 \mathrm{~nm}$. To analyze complex III activity, mitochondria were permeabilized in phosphate buffer containing $1 \%$ DOC and $2 \mathrm{mM}$ sodium azide, $0.25 \% \mathrm{v} / \mathrm{v}$ Tween- 20 and $75 \mu \mathrm{M}$ oxidized cytochrome $c$. The reaction was initiated by the addition of $0.1 \mu \mathrm{M}$ ubiquinol and reduction of cytochrome $c$ was detected as an increase in absorbance at $550 \mathrm{~nm}$. Assessment of complex IV activity was done by measuring the decrease in absorbance at $550 \mathrm{~nm}$ corresponding to the oxidation of reduced cytochrome c. A parallel reaction was set up for every experiment with the inhibitor of respective complexes to assure the specificity of the reaction.

Measurement of antioxidant enzyme activities. GPx activity was measured using the glutathione reductase (GR) coupled assay by spectrometrically following the decrease in the concentration of NADPH at $340 \mathrm{~nm}$. The reaction mix contained GSH $(2 \mathrm{mM}), \mathrm{NADPH}(0.4 \mathrm{mM}), \mathrm{GR}(1.7$ Units) and cell lysate corresponding to $50 \mu \mathrm{g}$ of protein in $100 \mathrm{mM}, \mathrm{pH} 7.4$ phosphate buffer. Reaction was initiated by adding $\mathrm{H}_{2} \mathrm{O}_{2}(240 \mu \mathrm{M})$ and decrease in absorbance at $340 \mathrm{~nm}$ was observed for $45 \mathrm{~s}$. MnSOD activity was analyzed in isolated mitochondria using SOD Assay Kit (Sigma-Aldrich, St. Louis, MO, USA).

Measurement of the mtDNA copy number. The copy number of mtDNA was estimated by utilizing the total cellular DNA to quantitative real-time PCR using iQ5 Multicolour real-time PCR detection system (Bio-Rad, Hercules, CA, USA). To amplify the gene segments, primer sequences used were: for mitochondrial NADH dehydrogenase subunit I (ND1), ND1-F: $5^{\prime}$-CTAGCCATCATT CTACTATCAAC-3' and ND1-R: $5^{\prime}$-AGGAGTAATCAGAGGTGTTC-3'; and for cytochrome $c$ oxidase (CO2), CO2-F: $5^{\prime}$-TGCTTCCTAGTCCTGTATG- $3^{\prime}$ and CO2-R: $5^{\prime}$-GCGTCTGAGATGTTAGTATTAG-3'. The normalization of the reactions was carried out by amplification of nuclear DNA controls, namely cyclophilin B (СypB) with primer sequence: CypB-F: $5^{\prime}$-ACCTACGAATTGGAGATGAA-3' and CypB-R: $5^{\prime}$-CCTTGATTACACGATGGAATT-3'; and $\beta$-actin with primer sequence: $\beta$-actin-F: $5^{\prime}$-TCCCAGCACACTTAACTTAGC- $3^{\prime}$ and $\beta$-actin-R: $5^{\prime}$-AG CCACAAGAAACACTCAGG-3'. Relative copy number was calculated from the threshold cycle value (Ct value) using the $\Delta \Delta \mathrm{Ct}$ method as previously described. ${ }^{52}$ Each reaction was optimized, and the linearity was confirmed within an appropriate concentration range using genomic DNA from untransfected HEK293T cells.

The mitochondrial DNA content was quantified by utilizing a fluorometric assay where an increase in SYBr Green (Invitrogen Molecular Probes) fluorescence because of higher DNA binding was quantified as a measure of the amount of DNA content. Equivalent amounts of mitochondria were incubated with saturating amounts of SYBr-Green dye and fluorescence was observed at $520 \mathrm{~nm}$.

Aconitase activity. Isolated mitochondria were utilized to measure the enzymatic activity of mitochondrial matrix protein aconitase according to the procedure described by Pierik et al..$^{53}$

DNA damage. Damage to DNA was detected as formation of double-stranded breaks. Cells adhered over a coverslip were fixed with IC Fixation buffer (Invitrogen) for $15 \mathrm{~min}$ at room temperature, followed by treatment with $90 \%$ alcohol for $7 \mathrm{~min}$. Cells were washed with PBS and incubated with blocking solution containing $0.05 \% \mathrm{lg}$ free BSA and $0.05 \%$ Triton-X 100 for $30 \mathrm{~min}$. After a wash with PBS, anti- $\gamma \mathrm{H} 2 \mathrm{AX}$ antibody was added and incubated for $1 \mathrm{~h}$ and $30 \mathrm{~min}$. Cells were washed three times with PBS and incubated with secondary antibody conjugated with Alexa-488. After washing two times with PBS, cells were mounted on ProLong Gold Antifade reagent with DAPI (Invitrogen). Cells were treated with $5 \mu \mathrm{M}$ cisplatin as positive control for the generation of double-stranded breaks by intercalating DNA strands or with $500 \mu \mathrm{M} \mathrm{CuSO}_{4}$ as control for ROS-mediated DNA damage. The formation of $\gamma \mathrm{H} 2 \mathrm{AX}$ foci was analyzed under Zeiss AxioObserver Z1 Apotome $2.063 \times$ oil NA 1.45. Images were acquired using Zeiss AxioCam MRm Camera and processed using Zeiss Axio vision Rel. 4.8 software. Images were zoomed digitally by Adobe Photoshop CS4.

Lipid peroxidation. Cells were pretreated with $25 \mu \mathrm{M} \mathrm{NaAsO}$ ( cells) or $4 \mathrm{mM} \mathrm{H}_{2} \mathrm{O}_{2}$ (yeast cells). After treatment, cells were harvested and washed with $1 \times$ PBS to completely remove the medium. Cells were resuspended in hypotonic buffer and sonicated at $30 \%$ amplitude for 3 pulses of $20 \mathrm{~s}$. Then, $1 \%$ thiobarbituric acid was added to the cell lysate followed by an incubation at $90^{\circ} \mathrm{C}$ for $1 \mathrm{~h}$ followed by addition of $250 \mu \mathrm{l}$ of $n$-butanol. The solution was centrifuged at $16000 \times g$ for $2 \mathrm{~min}$ for the separation of two phases. The supernatant was used to measure absorbance at $530 \mathrm{~nm}$.

Statistical significance. Calculation of statistical significance was done using two-tailed Student's t-test through Graph-Pad Prism 5 software (San Diego, CA, USA) unless otherwise mentioned; $P$-values are mentioned in figure legends.

\section{Conflict of Interest}

The authors declare no conflict of interest.

Acknowledgements. We thank Dr. Elizabeth A Craig for yeast strains and yeast-specific antibodies. We are obliged to Professor Rajan R Dighe and Ankur Sharma for their generous help in conducting ETC complex activity experiments. We acknowledge IISc FACS facility for performing flow cytometry experiments. We also thank Lakshmi Dinesh, Umakant Sahu and Keshav for their help in the study. This work was supported by Department of Science and Technology, Swarnajayanti Fellowship, DST/SJF/LS-01/2011-2012 (to PD'S) and DST-INSPIRE fellowship (to SS), Council of Scientific and Industrial Research Fellowship (to DS and PPS), Indian Institute of Science Research Associate Fellowship (to DS) and DBT Research Associate Fellowship (to HM).

1. Sies H. Oxidative stress: oxidants and antioxidants. Exp Physiol 1997; 82: 291-295.

2. Sies H. Biochemistry of oxidative stress. Angew Chem Int Ed Engl 1986; 25: 1058-1071.

3. Liu Y, Fiskum G, Schubert D. Generation of reactive oxygen species by the mitochondrial electron transport chain. J Neurochem 2002; 80: 780-787.

4. Lambeth JD. NOX enzymes and the biology of reactive oxygen. Nat Rev Immunol 2004; 4 : 181-189.

5. Finkel T. Signal transduction by reactive oxygen species. J Cell Biol 2011; 194: 7-15.

6. Nishikawa T, Edelstein D, Du XL, Yamagishi S, Matsumura T, Kaneda Y et al. Normalizing mitochondrial superoxide production blocks three pathways of hyperglycaemic damage. Nature 2000; 404: 787-790.

7. Baynes JW. Role of oxidative stress in development of complications in diabetes. Diabetes 1991; 40: 405-412.

8. Le Bras M, Clement MV, Pervaiz S, Brenner C. Reactive oxygen species and the mitochondrial signaling pathway of cell death. Histol Histopathol 2005; 20: 205-219.

9. Ceccarelli J, Delfino L, Zappia E, Castellani P, Borghi M, Ferrini S et al. The redox state of the lung cancer microenvironment depends on the levels of thioredoxin expressed by tumor cells and affects tumor progression and response to prooxidants. Int J Cancer 2008; 123: $1770-1778$.

10. Oberley LW, Buettner GR. Role of superoxide dismutase in cancer: a review. Cancer Res 1979; 39: 1141-1149.

11. Oberley TD, Oberley LW. Antioxidant enzyme levels in cancer. Histol Histopathol 1997; 12 : 525-535.

12. Sena LA, Chandel NS. Physiological roles of mitochondrial reactive oxygen species. Mol Cell 2012; 48: 158-167.

13. Kroemer G. Reed JC. Mitochondrial control of cell death. Nat Med 2000; 6: 513-519.

14. Ott M, Robertson JD, Gogvadze V, Zhivotovsky B, Orrenius S. Cytochrome c release from mitochondria proceeds by a two-step process. Proc Natl Acad Sci USA 2002; 99: 1259-1263.

15. Pasinelli P, Houseweart MK, Brown RH Jr., Cleveland DW. Caspase- 1 and -3 are sequentially activated in motor neuron death in $\mathrm{Cu}, \mathrm{Zn}$ superoxide dismutase-mediated familial amyotrophic lateral sclerosis. Proc Natl Acad Sci USA 2000; 97: 13901-13906.

16. Pervaiz S, Clement MV. Hydrogen peroxide-induced apoptosis: oxidative or reductive stress? Methods Enzymol 2002; 352: 150-159.

17. Trachootham D, Alexandre J, Huang P. Targeting cancer cells by ROS-mediated mechanisms: a radical therapeutic approach? Nat Rev Drug Discov 2009; 8: 579-591.

18. Baird L, Dinkova-Kostova AT. The cytoprotective role of the Keap1-Nrf2 pathway. Arch Toxicol 2011; 85: 241-272.

19. Wang XJ, Sun Z, Villeneuve NF, Zhang S, Zhao F, Li Y et al. Nrf2 enhances resistance of cancer cells to chemotherapeutic drugs, the dark side of Nrf2. Carcinogenesis 2008; 29: $1235-1243$.

20. Jubinsky PT, Short MK, Mutema G, Morris RE, Ciraolo GM, Li M. Magmas expression in neoplastic human prostate. J Mol Histol 2005; 36: 69-75.

21. Jubinsky PT, Messer A, Bender J, Morris RE, Ciraolo GM, Witte DP et al. Identification and characterization of Magmas, a novel mitochondria-associated protein involved in granulocyte-macrophage colony-stimulating factor signal transduction. Exp Hematol 2001; 29: 1392-1402.

22. Sinha D, Joshi N, Chittoor B, Samji P, D'Silva P. Role of Magmas in protein transport and human mitochondria biogenesis. Hum Mol Genet 2010; 19: 1248-1262. 
23. Young TW, Mei FC, Yang G, Thompson-Lanza JA, Liu J, Cheng X. Activation of antioxidant pathways in ras-mediated oncogenic transformation of human surface ovarian epithelial cells revealed by functional proteomics and mass spectrometry. Cancer Res 2004; 64: 4577-4584.

24. Mukhopadhyay P, Rajesh M, Yoshihiro K, Hasko G, Pacher P. Simple quantitative detection of mitochondrial superoxide production in live cells. Biochem Biophys Res Commun 2007; 358: 203-208.

25. Roy S, Short MK, Stanley ER, Jubinsky PT. Essential role of Drosophila black-pearl is mediated by its effects on mitochondrial respiration. FASEB J 2012; 26: 3822-3833.

26. Mehawej C, Delahodde A, Legeai-Mallet L, Delague V, Kaci N, Desvignes JP et al. The impairment of MAGMAS function in human is responsible for a severe skeletal dysplasia. PLoS Genet 2014; 10: e1004311.

27. Turrens JF. Mitochondrial formation of reactive oxygen species. J Physiol 2003; 552 335-344.

28. Jubinsky PT, Short MK, Mutema G, Witte DP. Developmental expression of Magmas in murine tissues and its co-expression with the GM-CSF receptor. $J$ Histochem Cytochem 2003; 51: 585-596.

29. Ruiz-Ramos R, Lopez-Carrillo L, Rios-Perez AD, De Vizcaya-Ruiz A, Cebrian ME. Sodium arsenite induces ROS generation, DNA oxidative damage, HO-1 and c-Myc proteins, NF-kappaB activation and cell proliferation in human breast cancer MCF-7 cells. Mutat Res 2009; 674: 109-115.

30. Arthur JR. The glutathione peroxidases. Cell Mol Life Sci 2000; 57: 1825-1835.

31. Ray G, Batra S, Shukla NK, Deo S, Raina V, Ashok S et al. Lipid peroxidation, free radical production and antioxidant status in breast cancer. Breast Cancer Res Treat 2000; 59 163-170.

32. Dalle-Donne I, Aldini G, Carini M, Colombo R, Rossi R, Milzani A. Protein carbonylation, cellular dysfunction, and disease progression. J Cell Mol Med 2006; 10: 389-406.

33. Vaubel RA, Isaya G. Iron-sulfur cluster synthesis, iron homeostasis and oxidative stress in Friedreich ataxia. Mol Cell Neurosci 2013; 55: 50-61.

34. Imlay JA. Pathways of oxidative damage. Annu Rev Microbiol 2003; 57: 395-418.

35. Kuo LJ, Yang LX. Gamma-H2AX - a novel biomarker for DNA double-strand breaks. In Vivo 2008; 22: 305-309.

36. Sokol AM, Sztolsztener ME, Wasilewski M, Heinz E, Chacinska A. Mitochondrial protein translocases for survival and wellbeing. FEBS Lett 2014; 588: 2484-2495.

37. Schusdziarra C, Blamowska M, Azem A, Hell K. Methylation-controlled J-protein MCJ acts in the import of proteins into human mitochondria. Hum Mol Genet 2013; 22: 1348-1357.

38. Sinha D, Srivastava S, Krishna L, D'Silva P. Unraveling the intricate organization of mammalian mitochondrial presequence translocases: existence of multiple translocases for maintenance of mitochondrial function. Mol Cell Biol 2014; 34: 1757-1775.

39. Huang Y, Chen X, Liu Y, Roth C, Copeland C, McFarlane HE et al. Mitochondrial AtPAM16 is required for plant survival and the negative regulation of plant immunity. Nat Commun 2013; 4: 2558.

40. Ide T, Tsutsui H, Hayashidani S, Kang D, Suematsu N, Nakamura K et al. Mitochondrial DNA damage and dysfunction associated with oxidative stress in failing hearts after myocardial infarction. Circ Res 2001; 88: 529-535.
41. Keeney PM, Xie J, Capaldi RA, Bennett JP Jr.. Parkinson's disease brain mitochondrial complex I has oxidatively damaged subunits and is functionally impaired and misassembled. J Neurosci 2006; 26: 5256-5264.

42. Hatle KM, Gummadidala P, Navasa N, Bernardo E, Dodge J, Silverstrim B et al. MCJ/DnaJC15, an endogenous mitochondrial repressor of the respiratory chain that controls metabolic alterations. Mol Cell Biol 2013; 33: 2302-2314.

43. Dauer W, Przedborski S. Parkinson's disease: mechanisms and models. Neuron 2003; 39: 889-909.

44. Meiser J, Weindl D, Hiller K. Complexity of dopamine metabolism. Cell Commun Signal 2013; 11: 34.

45. Irvine GB, El-Agnaf OM, Shankar GM, Walsh DM. Protein aggregation in the brain: the molecular basis for Alzheimer's and Parkinson's diseases. Mol Med 2008; 14: 451-464.

46. Ross CA, Poirier MA. Protein aggregation and neurodegenerative disease. Nat Med 2004; 10(Suppl): S10-S17.

47. Negre-Salvayre A, Coatrieux C, Ingueneau C, Salvayre R. Advanced lipid peroxidation end products in oxidative damage to proteins. Potential role in diseases and therapeutic prospects for the inhibitors. Br J Pharmacol 2008; 153: 6-20.

48. Tagliati F, Gagliano T, Gentilin E, Minoia M, Molè D, Delgi Uberti EC et al. Magmas overexpression inhibits staurosporine induced apoptosis in rat pituitary adenoma cell lines. PLoS One 2013; 8: e75194.

49. D'Autreaux B, Toledano MB. ROS as signalling molecules: mechanisms that generate specificity in ROS homeostasis. Nat Rev Mol Cell Biol 2007; 8: 813-824.

50. Liu Q, D'Silva $P$, Walter W, Marszalek J, Craig EA. Regulated cycling of mitochondrial Hsp70 at the protein import channel. Science 2003; 300: 139-141.

51. Spinazzi M, Casarin A, Pertegato V, Salviati L, Angelini C. Assessment of mitochondrial respiratory chain enzymatic activities on tissues and cultured cells. Nat Protoc 2012; 7 : 1235-1246.

52. Livak KJ, Schmittgen TD. Analysis of relative gene expression data using real-time quantitative PCR and the 2(-Delta Delta C(T)) method. Methods 2001; 25: 402-408.

53. Pierik AJ, Netz DJ, Lill R. Analysis of iron-sulfur protein maturation in eukaryotes. Nat Protoc 2009; 4: 753-766.

(c) (i) (2) Cell Death and Disease is an open-access journal published by Nature Publishing Group. This work is licensed under a Creative Commons Attribution-NonCommercialShareAlike 3.0 Unported License. The images or other third party material in this article are included in the article's Creative Commons license, unless indicated otherwise in the credit line; if the material is not included under the Creative Commons license, users will need to obtain permission from the license holder to reproduce the material. To view a copy of this license, visit http://creativecommons.org/licenses/ by-nc-sa/3.0/

Supplementary Information accompanies this paper on Cell Death and Disease website (http://www.nature.com/cddis) 